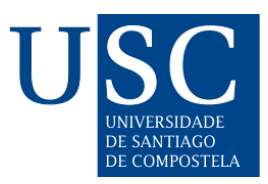

\title{
LOS INTERESES DE LA FEDERACIÓN DE RUSIA EN AMÉRICA LATINA COMO ESPACIO ESTRATÉGICO DENTRO DE UN MUNDO MULTIPOLAR
}

The interests of the Russian Federation in Latin America as a strategic space within a multipolar world

Silvia Marina Rivas de Hernández iD

Profesora de Relaciones Internacionales de la Universidad de El Salvador, El Salvador

Recibido: 21/11/2020; Aceptado: 27/02/2021

\section{Resumen}

A principios del siglo XXI con la ascensión de Vladimir Putin a la presidencia, la Federación de Rusia consolidó una actividad internacional más global a partir de estrategias marcadas en el establecimiento y fortalecimiento de relaciones diplomáticas, económicas y políticas con países sobresalientes de otras latitudes. Su finalidad ha sido lograr alcanzar su interés prioritario: reemerger como potencia global dentro de la estructura internacional. Así, Rusia amplió su espectro de acción exterior más allá del diplomático, incluyendo apertura de relaciones comerciales con la venta de armamento y la inversión en energía, moviéndose así hacia un acercamiento mayor con otros actores regionales de espacios como América Latina.

Utilizando el realismo estructural propuesto por Keneth Waltz y su variante de realismo ofensivo bajo los supuestos de Mearsheimer, se describen los intereses de la Federación de Rusia en la región latinoamericana, con especial énfasis en los países sudamericanos y México, lo que podría colocarle en consecuencia, como potencia global dentro de la estructura internacional vigente a través de la influencia en zonas extrarregionales. Por otra parte, se explica cómo la predominancia histórica de Estados Unidos sobre Latinoamérica se vería mermada, en la medida que Rusia logre formar parte de las potencias con influencia en la región. A pesar de que los factores iniciales de apertura al fortalecimiento de las relaciones rusolatinoamericanas se encuentren debilitados, los países latinoamericanos siguen sosteniendo la relación con Rusia, aunque se vean reducidas a términos diplomáticos y culturales. Los esfuerzos de Rusia en términos de cooperación sanitaria hacia algunos países en la región de cara al combate de la COVID19, marcará el poder de influencia y de consolidación del Estado ruso como socio en Latinoamérica durante los próximos años.

Palabras clave: Rusia; América Latina; Relaciones Internacionales; multipolaridad.

\begin{abstract}
At the beginning of the 21st century with the accession of Vladimir Putin to the presidency, the Russian Federation consolidated a more global behavior based on strategies marked in the establishment and strengthening of diplomatic, economic and political relations with outstanding countries of other latitudes in order to achieve its priority interest: reemerge as a global power within the international structure.
\end{abstract}


Thus, Russia broadened its spectrum of foreign action beyond the diplomatic, moving towards a greater rapprochement with other regions such as Latin America.

Using structural realism in its offensive variant proposed by Mearsheimer, the interests of the Russian Federation in the Latin American region are described, with special emphasis on the South American countries and Mexico, which could place it accordingly, as a global power within the structure. Current international influence through influence in extra-regional areas. On the other hand, it explains how the historical predominance of the United States over Latin America would be diminished, to the extent that Russia manages to be part of the powers with influence in the region. Even though, the initial opening factors to the strengthening of Russian-Latin American relations are weakened, the Latin American countries will continue to maintain their relationship with Russia, although they are reduced to diplomatic and cultural terms. The North American elections in November and the efforts of Russia in terms of health cooperation with some countries in the region in the fight against COVID19, will mark the power of influence of both States in the coming years.

Keywords: Russia; Latin America; International Relations; multipolarity.

\section{INTRODUCCIÓN}

El final del siglo XX estuvo marcado por la fragmentación de una de las dos grandes potencias mundiales en el entorno de la Guerra Fría: la Unión de Repúblicas Socialistas Soviéticas. En 1991, la URSS se separó en 15 repúblicas independientes. La Federación Rusa, bajo la administración de Boris Yeltsin, asumió los espacios en las organizaciones multilaterales como Estado heredero de la URSS (Simonof, 1994); sin embargo, ante el desmembramiento del territorio ex- sovietico y los problemas que económica y políticamente venía teniendo desde el período de Breznev, esta quedó bastante débil como para considerarse un actor estatal con la misma fuerza que representó la URSS en el periodo anterior (Schulze, 1985), contexto aprovechado por los Estados Unidos para expandir su influencia hacia el antiguo espacio soviético.

Las actitudes de Rusia en la posguerra fría en un principio se caracterizaron por pretender una alianza con occidente, buscando un tratamiento entre pares en organismos como la UE y el Grupo de los 7 (CIDOB, 2010). Este acercamiento no encontró una respuesta favorable ni fue recibida como una relación entre iguales, sino que, se percibió como un Estado débil pero necesario en el concierto de naciones. En el caso de la OTAN, se iniciaron algunos diálogos con Rusia para la inclusión de Polonia, Rumania y Hungría, como nuevos miembros de la organización, debido a que los 3 países fueron miembros del Pacto de Varsovia (Ecu Red, s.f.); restando así territorios de influencia histórica rusa y soviética, cuestión aceptada a regañadientes por el Kremlin (Rühle, 2015).

A la llegada de Vladimir Putin al poder en 1999 como presidente interino, la situación rusa seguía siendo la misma: un Estado heredero de la Unión Soviética, pero que no era considerado como un igual por sus interlocutores -según la clase política rusa- justificando en adelante posiciones más agresivas sobre temas sensibles a sus intereses nacionales. Varios acontecimientos sostenidos los primeros años del siglo XXI, como las llamadas Revoluciones de Colores en Ucrania, Georgia y Kirguistán, así como la ampliación de la OTAN en 2004 hacia los Estados bálticos, fue considerada por la administración Putin como un agravio a las aspiraciones rusas en su extranjero próximo, por lo que, se emprendió una política exterior más proactiva y vinculada a los sentimientos de patriotismo ruso, sosteniendo la doctrina fundada por Yevgueni Primakov, basado en una política 
exterior multipolar (CIDOB, 2010, pág. 495), reforzando su posición con respecto a las pretensiones de seguir manteniendo como punto de honor su influencia en la zona euroasiática ${ }^{1}$.

En cuanto a Asia Oriental, Rusia, estableció una fuerte alianza con China a través de su pipeline diplomacy basada en la venta de hidrocarburos y el apoyo en organizaciones multilaterales como BRICS, Organización de Cooperación de Shanghái y el Banco Asiático de Inversión e Infraestructura (Leiva Van de Maele, 2017).

En términos de acciones transhemisféricas, Rusia aprovechó el giro de los intereses estadounidenses hacia Medio Oriente, en específico en las guerras de Afganistán e Irak, para fortalecer los lazos de relación diplomática y económica con América Latina, tanto en países tradicionales tales como Cuba, México y Nicaragua, al igual que las amplió con Venezuela, Argentina y Brasil; poniendo especial énfasis en este último a quien ha considerado socio estratégico y miembro de BRIC y G20 (CIDOB, 2010, pág. 496).

Actualmente, la ampliación de relaciones estratégicas a nivel global trajo réditos para Rusia ante la idea de la multipolaridad democrática, estableciendo mayor presencia en países latinoamericanos, lo que significó mucho tratándose del área de influencia histórica de los Estados Unidos. Esta oportunidad fue posible como consecuencia de tres premisas elementales: en primera instancia gracias a la relación económica a través de la venta de armamentos a varios países en la región entre los que se destacan Venezuela, Brasil y Uruguay ${ }^{2}$; como segunda premisa, Rusia, ofreció sus servicios como contratista en proyectos energéticos que incluyen el know how en la promoción de la posibilidad de generar energía nuclear, y como tercera situación el aprovechamiento de la posición anti estadounidense de gobiernos considerados de izquierda en el hemisferio durante la primera década del nuevo siglo (Garay Vera, 2010).

Esto dio como resultado que la percepción de una Rusia de la posguerra fría anclada a su espacio euroasiático fuera reemplazada por el resurgimiento de una potencia de alcance global. A diferencia de las relaciones soviético- latinoamericanas basadas en una situación con remarcada atención política y partidaria (Varas, 1987), el comportamiento exterior de la Federación parecía indicar que buscaba un nuevo papel internacional en el seno de un Sistema Multipolar, adoptando una estrategia disuasoria hacia Estados Unidos al posicionarse como aliado estratégico de ciertos Estados latinoamericanos con características geopolíticas importantes como Venezuela, Brasil, Argentina y Nicaragua ${ }^{3}$.

Con la pandemia de la COVID19 experimentada a nivel mundial desde inicios del 2020, Rusia, ha elaborado una vacuna experimental nombrada Sputnik V, la cual ha sido sometida a pruebas masivas a inicios de septiembre, compitiendo con otras vacunas procedentes de países como China, Estados Unidos, Alemania, Reino Unido y Cuba. El éxito de Sputnik V puede significar para Rusia una plataforma de influencia y control estratégico en otros países, definitiva para consolidar su papel de potencia global en la estructura de un Sistema multipolar compartido con Estados Unidos y China, objetivo claro del presidente Putin desde su llegada al poder hace dos décadas.

El desarrollo de esta temática se hará a través de una investigación documental, la cual se define como aquella investigación que parte de una serie de métodos y técnicas dedicadas a la recopilación, interpretación y presentación de la información coherente y consistente del fenómeno investigado, en aras de generar nueva información científica (Calduch Cervera, 1998). Así, la ejecución del presente trabajo se realizará a través de la recopilación y procesamiento de información en diversas fuentes documentales materiales y digitales, las cuales incluyen documentos escritos, vídeos y entrevistas a representantes de gobierno. Puesto que la investigación es documental, el nivel del 
trabajo es descriptivo, estableciendo las características de la política exterior de Rusia desde el período de Leonid Brézhnev, el desmembramiento de la URSS hasta la actualidad, así como una descripción de los rasgos geopolíticos de América Latina, que le convierte en un espacio estratégico para el fortalecimiento de las relaciones diplomático-económicas con países específicos en la región y en los cuales las posibilidades de cumplimiento de metas y objetivos sea mayor, de manera que, la relación entre ambos factores nos lleve a inferir los intereses rusos en América Latina a partir de su doctrina de multipolaridad.

El análisis de documentos se apoyará en la utilización del realismo estructural de Kenneth Waltz como marco teórico, el cual concibe al sistema internacional como anárquico, al igual que sus antecesores realistas, con algunas observaciones: si bien la relación entre los Estados es entrópica, está determinada por la existencia de una estructura basada en las capacidades de cada una de las unidades; sin embargo y a diferencia de los realistas, para Waltz, el fin de los Estados no es la acumulación de poder, sino que el poder, se convierte en el vehículo para obtener su fin, es decir la seguridad, entendida como la supervivencia del Estado y continuidad de una estructura internacional ventajosa (Vargas Hernández, 2009). Si la estructura vigente no es beneficiosa para el Estado, este emprenderá en la medida de sus capacidades y entorno algunas acciones tendientes a romper con esta. Por otra parte, sobre la misma corriente del Realismo Estructural, Herz, explica el porqué de las acciones emprendidas por los Estados, las cuales no siempre se pueden clasificar como beligerantes, sino que estas se encuentran condicionadas por la percepción de seguridad frente a otros, por lo que, la incertidumbre es el elemento principal que determina el comportamiento en términos defensivos u ofensivos (Terradas, 2009).

El realismo estructural en su variante ofensiva de Mearsheimer establece como principio la incertidumbre del Estado dentro del entorno anárquico, lo que acompaña la revisión constante de los Estados para la continuidad de la estructura o su ruptura. En este último escenario, será el hombre de Estado quien, a través de su capacidad de persuasión, logre convencer a la población e instituciones estatales para que la expansión y el comportamiento ofensivo en términos de proactividad y activismo en la política exterior se considere como obligatoria para la supervivencia del Estado y su prestigio (Moure Peñín, 2015). Aplicando estos supuestos a la problemática que concierne a este trabajo, es claro que la estructura internacional establecida en la posguerra fría no fue del todo beneficiosa para Rusia,- a pesar que la desintegración de la URSS le brindó a la nueva Federación una buena cantidad de recursos minerales dentro de su territorio-; empero, redujo su área de influencia y poder en la zona euroasiática, si se compara con el que habría tenido de lograr una especie de confederación con preponderancia rusa, en especial en asociación con Ucrania (Plokhy, 2015).

Ante el giro de Estados Unidos en su política exterior con énfasis en el Medio Oriente, la Federación de Rusia aprovechó en su momento un contexto económico y político más favorable para presionar hacia una multipolaridad a través de alianzas pragmáticas con países como China y la creación de foros multilaterales entre los que se destaca el grupo BRICS, de igual manera la presencia del Estado ruso como miembro observador de organizaciones extra hemisféricas en la que, para el caso de América Latina sobresalen la Unión de Naciones Suramericanas (UNASUR)estancada actualmente-, la Organización de los Estados Americanos (OEA), Asociación de Estados del Caribe, entre otras, por lo que, ante la amplia participación e involucramiento de Rusia en la agenda internacional no puede dejarse de lado un actor tan importante, consolidando la existencia de un Sistema Multipolar. 


\section{CARACTERÍSTICAS DE LA POLÍTICA EXTERIOR RUSA}

La política exterior se define de acuerdo con Rafael Calduch como "aquella parte de la política general formada por el conjunto de decisiones y actuaciones, mediante las cuales se definen los objetivos y se utilizan los medios de un Estado para generar, modificar o suspender sus relaciones con otros actores de la Sociedad Internacional" (Calduch Cervera, 1993, pág. 34). En consonancia con este concepto, la política exterior no puede verse apartada de la política interna, dado que es un elemento de la labor estatal, a diferencia que esta se ejecuta fuera del territorio.

La política exterior pretende cumplir con las aspiraciones del Estado en cuanto a su lugar en el concierto de naciones y la estructura internacional en general, por lo que, es necesario que los gobernantes y sus gabinetes determinen las metas y los objetivos de esta política. Las actuaciones con respecto a ciertos homólogos o situaciones internacionales serán aprovechadas en la medida que se obtengan ventajas de cara al cumplimiento de lo establecido en la elaboración de la política exterior estatal.

La proyección de los Estados está muy arraigada con una serie de elementos internos que condicionan sus aspiraciones y su comportamiento exterior tales como: factores sistémicos, ${ }^{4}$ atributos nacionales y rasgos idiosincráticos. La relación entre estos componentes determina la conducta reiterada dentro de la estructura internacional, la cual se desarrolla con base en los objetivos y metas que pretendan lograr en la interacción con otros Estados o actores internacionales, por lo que, su comportamiento podría resultar diferente en ciertos temas y contextos (Pearson \& Rochester, 2000). Esta conducta se encuentra manifestada en la ejecución de diferentes acciones estatales: alianzas, campo de acción y modus operandi.

En ese orden de ideas, dentro del presente trabajo se abordarán los elementos que condicionan el comportamiento y la política exterior de la Federación Rusa, a la vez que se realiza una comparación con los factores que caracterizaron la política exterior de la URSS a partir del período de Leonid Brézhnev (1966-1982) a la actualidad, sin ahondar en los rasgos que determinan su acercamiento con América Latina, puesto que se expondrá en el apartado 4 de este documento. Así mismo, se describirá de brevemente el tema de la identidad nacional y sus implicaciones en el comportamiento del Estado ruso dentro de la estructura internacional.

\subsection{Las alianzas en la política exterior: de la Unión de Repúblicas Socialistas Soviéticas a la Federación de Rusia}

Las alianzas en la política exterior se definen como acuerdos entre Estados que proporcionan asistencia mutua en términos militares. Estos instrumentos permiten tener beneficios ante amenazas externas, no obstante, también conllevan riesgos en los términos que estas hayan sido establecidas (Pearson \& Rochester, 2000, págs. 115-116)

Para el caso ruso, es necesario remontarse al pasado soviético, cuando las alianzas militares en términos formales estaban determinadas por el Pacto de Varsovia. Esta organización fue creada en 1955 y tenía como integrantes a los países comunistas de Europa del Este bajo la influencia de la URSS. ${ }^{5}$ Sus objetivos se enmarcaron en la modernización del armamento y defensa frente a la OTANcreada en 1949-; sin embargo, años después fue utilizada para hacer frente a iniciativas antisistema dentro de los Estados miembros ${ }^{6}$ (Enciclopedia de Historia, 2018). El recurso a la intervención 
militar bajo estas situaciones se conoció como Doctrina Brézhnev, ${ }^{7}$ bajo la cual la URSS y los países miembros podían intervenir militarmente en otros Estados parte, a fin de detener los movimientos contrarrevolucionarios. Con este principio los soviéticos consolidaron su dominio en Europa del Este.

Fuera de la región, existieron ayudas en el campo militar dirigido a países comunistas como Cuba, Corea del Norte, Laos y Vietnam, así como a fuerzas insurgentes en las guerras civiles de otros países a través del Partido Comunista Soviético (PCUS); para Brézhnev era importante expandir el campo geopolítico a través de la ayuda a los movimientos de liberación nacional bajo la política de internacionalismo socialista (CIDOB, 2010, pág. 493).

A la llegada de Gorbachov al poder, el Pacto de Varsovia perdió peso en la agenda soviética ante la necesidad de reducción del gasto militar y la prioridad del nuevo líder por ganar la confianza de occidente. Sus esfuerzos por convencer sobre la reestructuración económica y política de la URSS, contenidas en la Perestroika, incluyeron la búsqueda de cooperación de Europa y Estados Unidos. Así las cosas, Gorbachov realizó una serie de acciones tendientes a disminuir la influencia y ayuda en países como Angola, Camboya, Cuba y Etiopía, que se consideraron un freno a la economía (Marquez Díaz, 2014).

A este tenor, el gobierno soviético retiró las tropas de Afganistán en 1989 a raíz de las presiones económicas y disminuyó sus efectivos en los países de Europa del Este desde 1987, lo que significó el abandono de la doctrina Brézhnev; este movimiento fue la clave para que Hungría, Checoslovaquia y Polonia lograran procesos de democratización, así como el inicio de la unificación alemana a partir de 1989, cuya expresión máxima fue la caída del Muro de Berlín en noviembre de ese año. Lo ocurrido en la búsqueda de una mejor imagen ante occidente, conllevó a que el Pacto de Varsovia se tambaleara en especial con la inclusión de Alemania Oriental a la OTAN; para 1991 esta alianza fue disuelta y las tropas soviéticas se retiraron completamente de Hungría y Checoslovaquia ese mismo año, al igual que lo hicieron en Polonia hasta 1993 (Deustch Welle, 2015).

Con el desmembramiento de la URSS, las alianzas militares se quedaron en segundo plano y se concentraron esfuerzos para la entrega de los arsenales nucleares soviéticos por los países que conformaron esta unión mediante lo acordado en el Tratado de Lisboa de 1992, bajo el que todo este armamento pasó a manos de Rusia en un proceso que duró hasta 1995. Con respecto a las bases militares soviéticas en el extranjero, Rusia mantiene instalaciones en Armenia, Kazajstán, Bielorrusia y la base naval de Tartus en Siria por considerarlas de bajo coste y altamente estratégicas, esta última le ha sido tan importante como para intervenir de lleno en el conflicto sirio actualmente (Marquez Díaz, 2014, pág. 23).

Mientras tanto durante los primeros años de la posguerra fría, el comportamiento de Rusia con respecto a la ampliación de la OTAN fue cauto y se permitió que Polonia y Hungría presentaran sus candidaturas para ser admitidos como miembros de la Organización, aprovechando la posición prooccidental de Yeltsin y su canciller Kozyrev. En contrapartida, en mayo de 1992 se firma el Tratado de Seguridad Colectiva cuyos miembros fueron Armenia, Bielorrusia, Rusia, Kazajistán, Kirguizistán y Tayikistán; este tratado pretendía unificar esfuerzos para el combate al crimen organizado y el terrorismo, no obstante, quedó en desuso durante la década de los 90, por lo que recibió un impulso en 2002, cuando el tratado se renovó y se transformó en la Organización del Tratado de Seguridad Colectiva (OTSC) con los mismos objetivos, pero ampliando su radio de interacción con otras organizaciones multilaterales de la misma naturaleza como la OTAN (Marquez Díaz, 2014, pág. 25). 
En 1995, la visión prooccidental del gobierno ruso tomó un giro distinto a causa de la intervención de la OTAN en el conflicto yugoslavo, tensión que condujo a presiones dentro del Kremlin por una política exterior más imparcial e independiente. La sucesión de Kozyrev por Yevgeny Primakov como canciller trajo a Rusia una nueva forma de pensamiento en su accionar exterior, esta vez, basada en una idea de multipolaridad con el fin de convertirse en un contrapeso a una unipolaridad rígida de los Estados Unidos, en los que sobresalió el descontento ruso por los bombardeos de la OTAN en Serbia en el marco del conflicto kosovar (CIDOB, 2010, pág. 495).

Con la renuncia de Yeltsin al poder ruso en 1999 y el ascenso de Vladimir Putin como presidente de la Federación en el 2000, Rusia poco a poco dejó el realismo defensivo que le caracterizó durante la época de los 90, para dar paso a una consolidación estratégica que le permitiría ejecutar acciones cada vez más ofensivas, como quedó demostrado en la intervención rusa en el conflicto de Georgia en 2008, durante la administración de Dimitri Medvedev.

En los años 2000 se inició un proceso de fortalecimiento del Estado ruso a través de un refuerzo tanto en las capacidades militares como económicas: tomando ventaja de los precios altos de los hidrocarburos experimentados en la primera década del siglo XXI. Rusia pagó varios de los empréstitos realizados en el período de Yeltsin, contexto que le permitió elevar el gasto militar y dar un empuje a la industria de armamentos en mercados de países emergentes para posicionarse de nuevo como potencia desde una óptica multipolar.

Para lograr esa fortaleza militar rusa después de la primera guerra de Chechenia -donde el ejército ruso quedó derrotado-, fue necesaria una reestructuración de las fuerzas armadas y lograr no solo el cese del conflicto checheno, sino una resolución que dejara ventajas para Rusia, manteniendo el territorio de la Federación como tal y disipara las ideas separatistas de Chechenia y otras regiones que se plantearan la posibilidad de independencia. ${ }^{8}$

En 2005, Rusia dio un impulso a la OTSC, mediante ejercicios militares conjuntos entre sus miembros, dándole a este país un despegue importante en la influencia militar dentro de la esfera ex soviética y generando espacios de defensa importantes ante la reciente expansión de la OTAN en 2004 (Marquez Díaz, 2014, pág. 26). Con las reformas a las fuerzas armadas y la industria militar en crecimiento, se inició con más pujanza una estrategia de disuasión más que de cooperación entre Rusia y occidente, a raíz de dos momentos: la ampliación de la OTAN en los países ex- soviéticos y la proliferación de gobiernos prooccidentales en países como Ucrania, Georgia y Kirguistán por medio de las revoluciones de colores.

Durante la Cumbre de la OTAN de 2008 en Bucarest, Rumanía, la organización se plantea la admisión de Ucrania y Georgia como estados miembros -a pesar de la oposición de Alemania y Francia-, situación considerada por Rusia como una provocación, agravada por el inicio de las negociaciones de un Tratado de Libre Comercio de la UE con Ucrania (Martínez Carmena, 2018).

Así, la intervención del ejército ruso en el conflicto de Georgia y Osetia del Sur en 2008 se calculó como una maniobra no solo militar, sino de política exterior, en la que se pretendió dejar claro los límites de los intereses rusos en el extranjero próximo. A nivel interno, sirvió como instrumento para justificar el aumento en el gasto militar y la renovación de armamentos También incluyó dentro de su estrategia de disuasión fortalecer la relación de la OTSC a nivel multilateral, creando en 2009 una fuerza militar conjunta que tiene como objetivo el rechazo de agresiones externas, la lucha antiterrorista y el combate al narcotráfico. Esto le ha hecho merecedor de una influencia directa sobre los espacios estratégico-militares de sus vecinos, inclusive a nivel de bases militares 
en Kirguistán en donde logró instalar algunas de ellas después del nacimiento de esta iniciativa denominada "fuerza de reacción rápida" (Leiva Van de Maele, 2017).

Aunado a los hechos anteriores, la situación con Ucrania ha escalado mediante la anexión de Crimea a la Federación, por medio de la aceptación de Rusia de un referéndum llevado a cabo en la región ucraniana del Donbás en 2014, lo que le acarreó al Estado ruso una serie de sanciones por parte de la UE y de Estados Unidos; situación que Rusia considera injusta, ya que ve el reconocimiento de Crimea como legítimo y compensatorio a las que considera agresiones por parte de occidente (Leiva Van de Maele, 2017, pág. 37).

Lo anterior, ha permitido que Rusia, a través del incremento de sus capacidades militares y económicas muestre una política exterior más asertiva, no solo en la región del Mar Negro con el caso de Crimea y la base naval de Sebastopol, sino que este tipo de acciones más ofensivas se trasladaron a los países del báltico pertenecientes a la OTAN, situación que se exacerbó entre 2015-2016, cuando se registraron más de 1,200 incidentes entre las fuerzas armadas rusas y los Estados miembros por sobrevuelos no autorizados (Soames, 2019). De la misma forma, ha entrado también en ciertos roces con Dinamarca y Canadá ante las pretensiones de los tres países árticos por extender su plataforma continental más allá de las 200 millas, alegando la pertenencia de la Dorsal Lamónosov, cuestión que por derecho ampliaría su jurisdicción de las aguas y el subsuelo, aprovechando el calentamiento global para dar factibilidad a la Ruta Marítima del Norte, esta pretensión ha incluido despliegues militares en las islas rusas ribereñas (García Estrada, 2020).

Si bien, las acciones de la Federación de Rusia hasta el momento no han dependido de una alianza militar para mostrarse fuertes, su comportamiento asertivo se justifica, a su parecer, por las constantes ampliaciones de la OTAN y la influencia de la UE en las zonas consideradas de influjo natural por formar parte de los territorios que pertenecieron al imperio ruso o a la ex URSS, por lo que la ampliación de sus acciones a otros espacios transhemisféricos, son parte de la estrategia ofensiva para romper con la estructura unipolar establecida por Estados Unidos y sus aliados occidentales, empujando a la consolidación de una estructura multipolar que colocaría a Rusia en una posición de potencia global.

\subsection{Campo de acción de la política exterior rusa: del regionalismo a lo global}

El campo de acción se concibe como el alcance de las actividades de la acción exterior de un país de acuerdo con sus intereses, los cuales pueden ser: globales, regionales u optar por el aislacionismo. El campo de acción está delimitado por la relación entre los objetivos de política exterior y capacidades económicas, políticas e inclusive militares de cada uno de los Estados para la consecución de lo proyectado (Pearson \& Rochester, 2000, pág. 117). Los Estados que optan por cierto aislacionismo fuera de sus fronteras regionales no siempre lo hacen en respuesta de una debilidad o falta de capacidades, sino que, dentro de los objetivos y fines de la política exterior del país no contempla la ruptura del statu quo, puesto que este le es beneficioso para sus pretensiones.

Bajo esta premisa, se describirá el desarrollo del campo de acción ruso en cuanto a su política exterior, pasando por los estadios de un campo de acción global con la bipolaridad, el regionalismo característico de Yeltsin y Kozyrev, hasta la multipolaridad con un regreso a los objetivos globales propuesta por Primakov y continuada por Putin y Medvedev. 
Desde la finalización de la Segunda Guerra Mundial, la URSS y Estados Unidos se embarcaron en una constante tensión por generar la mayor influencia a nivel mundial, lo que los llevó en ocasiones a enfrentarse en el apoyo a las fuerzas insurgentes y gubernamentales dependiendo la situación dentro del conflicto.

Durante el liderazgo de Brézhnev se continuó con el período de distensión iniciado por Jrushchov entre la URSS y los Estados Unidos, y, aunque parecía tambalearse por la intervención de los ejércitos del Pacto de Varsovia en Europa del Este y las políticas de contención de los Estados Unidos a través de la Doctrina de Seguridad Nacional para América Latina, ${ }^{9}$ logró mantenerse hasta 1979. En este período se obtuvieron avances significativos a nivel de acuerdos entre ambas potencias como el Tratado de No Proliferación Nuclear en el que se incluyó Reino Unido en 1968, y, en 1969 se inició el proceso de negociación para el Tratado sobre Misiles Antibalísticos conocido como SALT I por sus siglas en inglés, firmado en 1972 entre Carter y Brézhnev (Historia Siglo 20, 2003). Esta distensión se fue diluyendo debido a diferentes eventos como la invasión soviética en Afganistán, ${ }^{10}$ la revolución iraní, el triunfo de la revolución Sandinista en Nicaragua y el problema de la instalación de los misiles de medio alcance y misiles tomahawk en Europa Occidental, considerada como una agresión hacia la URSS por los países OTAN.

Las tensas relaciones entre ambos países escalaron a otros campos como el boicot a los Juegos Olímpicos de Moscú en 1980, en los que no se presentaron varios países occidentales, China e Irán, como protesta por la invasión soviética en Afganistán; en ese mismo orden, las sanciones económicas lideradas por Estados Unidos que incluyeron rubros como tecnología, hidrocarburos y trigo colocaron más peso a los problemas financieros ya experimentados por la Unión. Aunque la URSS y sus aliados boicotearon las Olimpiadas de Los Ángeles en 1984, esta maniobra no tuvo el efecto esperado (Marquez Díaz, 2014).

La llegada de Ronald Reagan a la presidencia estadounidense en 1981 reforzó la Doctrina de Seguridad Nacional en respuesta a los movimientos insurgentes en América Latina, que se vieron fortalecidos por el apoyo ideológico y táctico de la URSS y sus aliados transhemisféricos como Vietnam y Cuba; así Latinoamérica se vio envuelta en un constante conflicto que se tornó en una concepción casi divina entre el occidente cristiano y el comunismo ateo, cuestión que sirvió para enardecer las posiciones más conservadoras de la sociedad (Velásquez Rivera, 2002). Con la muerte de Brézhnev y el nombramiento de Yuri Andropov para su sucesión, la situación entre la URSS y Estados Unidos siguió igual, sin embargo, se experimentó un aumento en el gasto militar en ambas potencias.

En 1983, después del derribo de un vuelo comercial de Korean Airlines por los soviéticos, la situación volvió a puntos delicados entre las partes. En 1984 y ante la muerte de Andropov, se nombró a Konstantin Chernenko como líder de la URSS, el cual solamente ejerció el poder por trece meses, desde febrero de 1984 hasta abril de 1985, período en el que la situación económica y política se agudizó aún más, no solo por las sanciones impuestas por occidente sino por el lastre que significaba seguir con el conflicto afgano (Marquez Díaz, 2014).

Con Gorbachov marcando la diferencia entre los liderazgos anteriores y consciente de la mala situación soviética, se suavizaron las posiciones con respecto a occidente. En términos de relaciones diplomáticas y objetivos globales, Gorbachov buscó mostrar su apertura y buenas intenciones abriendo relaciones diplomáticas con Arabia Saudita, Corea del Sur e Israel, aliados conocidos de los Estados Unidos. Esta flexibilidad también se reflejó en el trato con los países de Europa del Este, no solo por el abandono de la Doctrina Brézhnev, sino que se permitió que cada Estado eligiera su 
propio sistema social, cuestión que derivó en el abandono del socialismo en la mayoría de casos, por lo que a inicios de los 90, el Consejo de Asistencia Mutua conocido como CAME fue disuelto, aunque las partes acordaron mantener vínculos multilaterales (CIDOB, 2010, pág. 494).

La Guerra Fría se fue disipando poco a poco y muestra de ello fue la Cumbre de Malta de diciembre de 1989, en la cual George Bush como presidente de los Estados Unidos y Gorbachov se reunieron para tratar distintos temas días después de la caída del Muro de Berlín. Durante aproximadamente cinco horas ambos líderes discutieron temas importantes entre los que se encontraban la reducción de armamento nuclear para lograr la desescalada de tensiones (Cortes, 2019). El líder soviético, conociendo la situación económica, política y social que estaba viviendo la URSS, propuso retirar el apoyo soviético a países en desarrollo, no obstante, seguía mostrando reticencia con el tema de Cuba y el sostenimiento brindado desde la revolución de 1959. A cambio de estas concesiones, Estados Unidos brindó apoyo económico y concedió a los soviéticos el trato de nación más favorecida, nuevos créditos y la promesa de no agresión militar (Marquez Díaz, 2014, pág. 18). Con todo este panorama, el campo de acción global de la Unión Soviética se redujo hasta su desmembramiento con la emergencia de Rusia y la Comunidad de Estados Independientes (CEI).

La Federación de Rusia, enfrentó en sus primeros años serios problemas económicos arrastrados desde la URSS, puesto que este país asumió la mayor parte de los compromisos económicos de la Unión Soviética generada durante la época de Gorbachov, una deuda que ascendía a más de 23 mil millones de dólares, la cual se vería aumentada por los empréstitos solicitados para superar la crisis de finales de los años 90 (Marquez Díaz, 2014). Los esfuerzos de la Federación de Rusia por mantener su espacio de influencia en la zona euroasiática se concentraron en la creación de la Comunidad de Estados Independientes (CEI), no obstante, esta organización no logró cumplir con las expectativas planteadas por los rusos, ya que varios de los países ex soviéticos tuvieron cierta desconfianza con las intenciones de la organización; pues tenían temor que esta fuera un proyecto que generara cooptación por la república más grande de la ex URSS, esto se reflejó en que los Estados miembros acordaron que la sede de la CEI se ubicara en Minsk y no en Moscú.

El campo de acción de la Federación Rusia se fue ampliando en un proceso moderado con la llegada de Y. Primakov como canciller, dado que este tomó una posición distinta a la de su predecesor, por lo que en ocasiones inclusive estuvo en desacuerdo con occidente sobre las intervenciones de la OTAN en los Balcanes. El Estado ruso fue muy activo dentro del grupo de contacto, pero se mantuvo prudente dadas las capacidades aún débiles en la unipolaridad. ${ }^{11} \mathrm{~A}$ finales de los noventa, el conflicto de Kosovo fue otro de los escenarios que permitió a Rusia desmarcarse un poco de la posición prooccidental y establecer voces alternativas ante la situación, concibiendo que la posición de Serbia era clara y justa, así como no dudó en declarar que los bombardeos de la OTAN no estaban basados en el Derecho Internacional. En ese contexto, trató de suavizar la posición occidental y se mostró contraria a los Estados Unidos, pero no se arriesgó a crear un problema diplomático del estilo soviético, dadas las desfavorables condiciones rusas después de la crisis económica de 1998, adoptando una posición defensiva en ese contexto (Kurjak, 2001)

En tanto, Primakov promovió la diversificación de aliados y áreas de interés en la política exterior rusa, de forma que estableció y reestableció relaciones con Estados importantes como países árabes entre los que se encuentra Siria, Egipto, Irán, entre otros; en Asia, renovó los lazos con China y la India; por último en América Latina se acercó a Venezuela, México y claramente Cuba (Sánchez Ramírez, 2010). Aunque estas acciones exteriores podrían parecer antioccidentales, la posición 
adoptada por Primakov fue pragmática sin concesionar los principios rusos, manteniendo un grado de flexibilidad aceptable para sostener su posición sin entrar en viejas rivalidades.

En el siglo XXI con Vladimir Putin a la cabeza de Rusia, la llamada Doctrina Primakov se sostiene, por supuesto con los matices que el presidente ruso ha dado a la política exterior desde su llegada al gobierno hace dos décadas; esta reemergencia de Rusia en la política internacional ha estado determinada por su proyección global, sin descuidar el espacio ex soviético como prioridad, uno de los ejemplos de este comportamiento ha sido el fortalecimiento de las relaciones exteriores de Rusia con países fuera del espectro euroasiático, como Brasil, China, India, Irán, Qatar, entre otros; no solo en el campo diplomático sino a través de lazos comerciales que ha logrado establecer con la venta de armamentos, hidrocarburos e inversiones en energía. Por otra parte, se reactivaron las relaciones con países que durante la Perestroika y el mandato de Yeltsin se habían dejado de lado, como la relación con Siria y Egipto que tomaron gran importancia después de la Primavera Árabe (Sánchez Ramírez, 2010, pág. 164).

Los ataques del 11 de septiembre en Estados Unidos fueron una prueba de las intenciones de Rusia con respecto a su antiguo rival, en esta ocasión el presidente Putin se mostró como aliado en la "Guerra contra el terrorismo" lanzada por los estadounidenses en Afganistán, así mismo apoyó los esfuerzos de la OTAN en la zona. Sin embargo, este entendimiento y cooperación tuvo su primer desavenencia en 2003 cuando Estados Unidos propuso ante la ONU la intervención en Irak, Rusia se opuso al igual que lo hizo Francia y bloquearon la intención de los norteamericanos dentro del Consejo de Seguridad. Ampliando este comportamiento, aunque Washington consideraba a Irán y Siria como Estados patrocinadores del terrorismo, los rusos siguieron estrechando relación con ellos, esto también con miras a establecer su independencia y búsqueda de la multipolaridad como contrapeso a los estadounidenses.

En ese sentido, aprovecharon el viraje de los Estados Unidos y sus intereses en Medio Oriente, fortaleciendo las relaciones diplomáticas y de comercio con países latinoamericanos cuyos gobiernos marcaron un distanciamiento de la influencia de los estadounidenses, como Argentina, Bolivia, Brasil y Venezuela, con este último hubo mayor acercamiento por sus recursos energéticos y oportunidades de inversión. Así con una política exterior diversificada más fortalecida desde el desmembramiento de la URSS, el canciller Lavrov en 2007 denunciaba lo poco democrático de una estructura internacional unipolar, concentrada en la supremacía americana, por lo que anunciaban con mayor fuerza sus intenciones de marcar una fractura en el statu quo (CIDOB, 2010, pág.500).

A inicios del siglo XXI, Rusia, se tornó más activa en sus vínculos internacionales dándole un impulso a los espacios multilaterales como BRIC, la Organización de Cooperación de Shanghái y la OTSC, dentro de las cuales tiene capacidad de maniobra como para establecer la agenda de estos organismos. En ese mismo orden, es destacable la posición de multirregionalismo del canciller Lavrov, en la que se propone la resolución de conflictos a través de mecanismos regionales, premisa que marcaría de facto la influencia de las potencias sobre zonas específicas, no obstante, esta propuesta también podría jugarle en contra a los rusos, en la medida que esa regionalización vaya fragmentando los niveles de influencia en el entorno ex soviético, contenido en diferentes áreas geográficas. Para solucionar este inconveniente, Rusia apoya ciertos movimientos regionales como aquellos dentro de la UE que consolidan la visión eurocéntrica, pero se opone a aquellos que le restan espacio en la zona considerada estratégica, como por ejemplo los acuerdos de vecindad entre la UE y los países cercanos al Mar Negro o el Cáucaso (Makarychev, 2011).

En 2015, después de las sanciones impuestas por occidente a raíz del problema de la anexión de Crimea a territorio ruso, la Federación estableció sus objetivos prioritarios en la Estrategia 
Nacional de Seguridad de la Federación de Rusia, la cual entre otras metas incluye la consolidación del país como potencia mundial, y para el cumplimiento de estas, las reforzó con la redacción de Los Objetivos Nacionales y Metas Estratégicas hasta 2024, decretado en 2018. Estos documentos han marcado los puntos de partida y llegada para la consolidación de una Rusia líder dentro de la estructura multipolar en diferentes aspectos, entre los que se destaca convertirse en una de las 5 economías más importantes a nivel mundial, así como desarrollar la Ruta del Norte en el espacio ártico, teniendo en cuenta que es el país con mayor frontera en la zona polar (De Freitas Coutinho, 2020).

Así las cosas, Rusia ha transitado por diferentes campos de acción dentro de su política exterior, cuestión que obedece a las capacidades económicas, políticas y militares en espacios de tiempo determinados, la influencia en su extranjero próximo y otros países más allá de Europa del Este se ha derivado de varias fuentes: desde los lazos históricos e identitarios, pasando por lo ideológico y últimamente a través de las relaciones comerciales que han logrado formar a través de la venta de armamento, hidrocarburos y energía, a la vez que junto a China forman un bloque de oposición a Estados Unidos, para consolidar la multipolaridad.

Si bien Rusia ha mantenido la idea de una multipolaridad democrática, su relación directa con regímenes que no comparten sistemas políticos democráticos, dejan en entredicho este argumento, lo que se puede observar más allá del discurso gubernamental, es el pragmatismo con el que ha manejado su política exterior para el logro de sus objetivos a través de acciones concretas en el campo comercial y político, tema que se ampliará en adelante.

\subsection{Modus Operandi: de lo ideológico a la relación comercial}

El modus operandi se refiere a los métodos o formas que utilizan los Estados para lograr sus objetivos y metas en política exterior (Pearson \& Rochester, 2000, pág. 118). Estos métodos transitan desde la diplomacia, las relaciones comerciales, la identidad compartida, la guerra hasta la intervención en asuntos internos de otros países.

Durante el período de la URSS, la política exterior fue manejada con el objetivo de expandir la revolución a nivel internacional, por lo que los factores de carácter político e ideológico, así como de tipo económico se concentraron en la ayuda a las luchas insurgentes como medio para lograrlo, en ese mismo sentido, los soviéticos promovieron ciertos principios del Derecho Internacional, en la medida que se adaptaran a las premisas ideológicas del comunismo y ampliara su influencia externa, como la autodeterminación de los pueblos, el respeto a la soberanía nacional y coexistencia pacífica (Glejdura, 1962). El fenómeno de la descolonización en las décadas de los 50’s a los 70’s sirvió de marco para apoyar las independencias de las colonias asiáticas y africanas ganando estos espacios dentro de la bipolaridad; por otra parte, la relación con Cuba después de la revolución de 1959 abrió la oportunidad para tener una comunicación más directa con los partidos comunistas y movimientos sociales de izquierda en América Latina.

Aunque la URSS propugnaba por la autodeterminación de los pueblos y la soberanía nacional como principios elementales del comunismo, la doctrina Brézhnev entraba en completa contradicción con estos, al intervenir a través de los ejércitos del Pacto de Varsovia en Hungría y Checoslovaquia. Claramente, en estos casos era indispensable mantener una amalgama fuerte en la zona de influencia, en especial frente a Estados Unidos que por esas mismas épocas llevaba a cabo estrategias de contención con la participación de sus tropas en Vietnam y los regímenes militares 
contrainsurgentes en Latinoamérica. Por su parte, los estadounidenses quisieron aprovechar un poco la situación de inestabilidad en Europa del Este para tratar de diezmar la economía soviética acercándose a clientes tradicionales de la URSS como la India, no obstante, este movimiento no fue fructífero ya que Brézhnev visitó de forma oficial el país con el fin de firmar una serie de acuerdos comerciales (Marquez Díaz, 2014).

En los años posteriores Andropov y Chernenko decidieron incrementar el gasto militar, habida cuenta de las iniciativas de defensa estadounidense, las cuales tuvieron más presencia con la llegada de Ronald Reagan a la Casa Blanca y la puesta en marcha de la Iniciativa de Defensa Estratégica ${ }^{12}$, asimismo se intensificó la cooperación de los soviéticos con grupos beligerantes en África y América Latina en aras de mantener la influencia en términos globales. Las sanciones impuestas a Moscú por la invasión a Afganistán contrajeron la economía ya bastante afectada, por lo que su modus operandi para seguirse manteniendo como potencia global se fue estrechando y prácticamente dejó en manos de países satélites el apoyo a organizaciones comunistas y grupos insurgentes envueltos en conflictos armados.

Con Gorbachov a la cabeza del Kremlin a mediados de los 80's, los objetivos de política exterior de la URSS no se volcaron hacia la exportación de la revolución a nivel planetario o la victoria del proletariado sobre el capitalismo. La situación de la URSS en ese momento necesitaba de una inyección urgente de inversión y cooperación para salvar la economía bastante afectada no solo por factores exógenos como las sanciones impuestas y la invasión a Afganistán sino también por factores endógenos entre los que se encontraba el descontento popular por las condiciones precarias de la sociedad, también aquejada por la poca productividad e innovación en sus productos, siendo menos atractivo para el mercado que estaba implementando mucha tecnología para mejorar la mercancía al igual que la producción en masa (Sahagún, 1989).

Para lograr la cooperación de occidente, Gorbachov tuvo que reformar el modus operandi debido al giro de los objetivos de política exterior durante la Perestroika, lo que implicaba retraerse de compromisos aceptados en períodos anteriores y desatenderse de los lazos con algunos países como Angola, Camboya, Etiopía y Cuba, en aras de obtener un espacio de distensión que le sirviera para ganarse la confianza de sus anteriores rivales. Por otra parte, la reducción de puntos beligerantes mostrando buena voluntad estuvo marcada por la salida de las tropas soviéticas en Afganistán y la aceptación del proceso de unificación alemana que implicaba la expansión de la OTAN a los territorios de la Alemania Oriental (CIDOB, 2010, pág. 494). Este modus operandi de carácter defensivo en términos de lograr concesiones importantes para la URSS se mantuvo hasta su finalización en diciembre de 1991.

Con el gobierno de Yeltsin, la Federación de Rusia se dio a la tarea de encontrar espacios que le permitieran seguir teniendo influencia dentro del área ex soviética actuando por una parte bajo la premisa de una organización multilateral que les facilitara establecer lazos de cooperación y ayuda mutua con su extranjero próximo, y, por otra la aceptación de occidente como socio a fin de superar la situación socioeconómica rusa que se venía enfrentando con anterioridad. El canciller Kozyrev consideró que era importante definir la nueva política exterior de Rusia al margen de la ideología comunista y la constante rivalidad con Estados Unidos, de forma que al tenerla clara, también definiría la nueva identidad del Estado, así se elaboró un modus operandi pro occidental que se enmarcara en el reconocimiento de Estados Unidos como potencia global respetuosa de los compromisos internacionales entre Estados, es decir una especie de "unipolaridad blanda" en la que la acción estadounidense se vería frenada por estas normas y acuerdos (CIDOB, 2010, pág. 495) 
De esta manera, Rusia se mostraría abierta y colaborativa al nuevo sistema internacional, con el fin de no tener un lugar menos privilegiado en la estructura unipolar y mantener su área de influencia a través de instrumentos como la CEI y el Tratado de Seguridad Colectiva con los países ex soviéticos. Hasta mediados de los 90 este modus operandi no experimenta mayor modificación, a pesar de la posición rusa con respecto a la crisis de los Balcanes, esto en parte porque Rusia no poseía las capacidades para influir en el grupo de contacto en torno al conflicto yugoslavo y apoyó las propuestas de Europa Occidental (Hernández Campos, 1997).

En los años subsiguientes, con Vladimir Putin en la presidencia, Rusia inició un proceso encaminado a obtener un espacio en la estructura internacional movilizando su política exterior hacia un modus operandi más activo. La presencia constante a través de lazos comerciales y las alianzas con economías emergentes como Brasil, China y la India se dirigieron a propugnar por un sistema multipolar que les otorgara las ventajas necesarias para considerarse como potencia global.

En ese sentido, la Federación estableció varias iniciativas que le permitieron formar vínculos estratégicos a nivel internacional, con base en la activación de relaciones con Estados que le brindaran beneficios de índole económica, militar y científica; así Putin buscó mediante giras de visita lograr acercamientos con países vecinos como las repúblicas ex soviéticas y algunos ex miembros del Pacto de Varsovia, cuestión que llamó la atención partiendo que estos actualmente forman parte de la OTAN. ${ }^{13}$ Así el modus operandi de acompañamiento prooccidental se vio resquebrajado cuando dentro de estas visitas del presidente ruso se incluyó a Corea del Norte, Irán, Irak y Cuba, países considerados por el gobierno de Estados Unidos como financistas del terrorismo en esa época. La asertividad con la que Rusia ha actuado desde inicios del 2000 se origina a partir de un mejor panorama económico a nivel doméstico que elevó la calidad de vida de la población y generó las oportunidades de inyectar capital a otras industrias (Sánchez Ramírez, 2010)

A sabiendas de la importancia de la industria militar rusa durante las décadas anteriores, en 2006 se dotó a la Comisión de la Industria de Armamentos con amplias facultades para impulsar la innovación y desarrollo de este rubro y a través de ello, incrementar la exportación de armas de empresas rusas con China y la India como clientes principales, quienes registraron compras del 2000 al 2010 por casi 30 millones de dólares entre ambos países (Sánchez Andrés, 2014)

En ese orden de ideas, para 2010 se aprobaron reformas dirigidas a la industria de defensa en aras de mejorar la producción de armamentos, teniendo validez hasta el año 2020, anteriormente, se habían aprobado otras reformas, pero las condiciones endógenas de la Federación no lo permitieron: la recesión económica de 1998 y la entrada al conflicto georgiano en 2008. En este sentido, se espera que al 2020 las fuerzas armadas rusas hayan renovado todo su armamento al $70 \%$. Durante este intervalo de tiempo se experimentaron constantes inyecciones de capital para la producción y necesidades internas. Aparte debe tratarse la industria de armamentos para la exportación, siendo uno de los nichos más importantes para su economía, solamente en los últimos años de la primera década del siglo XXI, las exportaciones rusas en armamento contabilizaron más de 15 mil millones de dólares, lo que se traducen no solo en réditos económicos, sino en relaciones comerciales que expanden el radio de influencia ruso (Sánchez Andrés, 2014).

Por otra parte, Rusia es consciente de la dependencia de los hidrocarburos y gas natural de Europa del Este, incluyendo Alemania, en este rubro se considera que, para el 2018 el $42 \%$ del abastecimiento europeo de estas materias primas provino de fuentes rusas (De Freitas Coutinho, 2020, pág. 14). El Estado ruso ha sabido utilizar esta ventaja para agenciarse el apoyo de los germanos en la construcción de gaseoducto Nord Stream 2, aunque ello le lleve a considerarles 
como un Estado disidente con respecto a la política de la UE frente a Rusia por la anexión de Crimea (Deustch Welle, 2018).

El desarrollo de una política exterior considerada por occidente en ocasiones agresiva ha llevado a que el modus operandi transite incluso por la intromisión en los asuntos domésticos de otros Estados, cuestión que Rusia había tratado de evadir hasta la situación de Osetia del Sur y Georgia en 2008. Con el conflicto de Siria, la Federación ha marcado sus puntos de interés en lo que considera espacios estratégicos, no solo por tratarse de gobiernos aliados sino por que la ruptura del statu quo marcaría una amenaza a la configuración geopolítica en Oriente Medio después de la invasión estadounidense en Irak. La importancia de la permanencia de Bashar Al Assad al frente del gobierno sirio es indispensable para mantener buenas relaciones con el país, lo que se traduce en el sostenimiento de su base militar en Tartus que le reporta grandes ventajas frente a las costas del Mediterráneo y los Estados colindantes pertenecientes a la OTAN; esto, más allá de Turquía con quien ha buscado acercamientos en paralelo junto con Irán estableciendo el proceso de Astaná para la solución del conflicto sirio (de Pedro, Martínez, \& Sökmen, 2018). Así, ganó colocarse como un jugador geopolítico en Medio Oriente.

Finalmente, las relaciones económicas y de alianzas militares en términos pragmáticos caracterizan el modus operandi de la Federación de Rusia en el siglo XXI, en su búsqueda por colocarse de nuevo como potencia global. A diferencia de la URSS, sus relaciones están basadas en el beneficio que pueden conceder a Rusia en la consolidación de un mundo multipolar como estructura internacional, sin importar la ideología de los Estados o el sistema político de sus aliados, para ellos, lo esencial se sitúa en el papel de estas relaciones con respecto a la consecución de los objetivos de política exterior.

\subsection{La identidad como factor de política exterior}

Para hablar de identidad nacional en términos laxos, es importante considerar a esta como una autopercepción dinámica y derivada de ciertos puntos de inflexión históricos, los cuales pueden, en su momento, modificar el concepto del "nosotros" y los "otros". La identidad nacional, en este caso, se ve reflejada en el comportamiento del Estado frente a sus homólogos y la interacción que establezca con ellos (Álvarez Portas, 2020). Aunque la teoría del realismo ofensivo no contempla este elemento, es necesario señalarlo por las implicaciones que la identidad nacional ha tenido en los procesos de toma de decisiones de las políticas gubernamentales, las cuales se ven reflejadas en la construcción del papel estatal en la estructura internacional.

En el caso ruso, la identidad y sus manifestaciones a través del nacionalismo han jugado en lo que va del siglo XXI un papel esencial para la legitimación de los objetivos y metas de política exterior como Estado. La caída del bloque soviético no solo afectó la percepción del "nosotros" ruso, sino que fue más allá con aquellos connacionales que fueron separados de Rusia como consecuencia de la independencia de las repúblicas soviéticas, cuestión que fue recibida como una humillación de occidente. Lo anterior generó un grave impacto en la autopercepción de los rusos, puesto que, los soviéticos en su momento se concibieron como los "salvadores de Europa", esto, a raíz de lo esencial que fue su desempeño para la derrota de la Alemania nazi, y, en consecuencia, el fin de la Segunda Guerra Mundial, esta concepción fue sostenida hasta la finalización de la guerra fría. La situación

a la que se veían sometidos en el momento de la transición de la bipolaridad hacia la unipolaridad 
estadounidense marcó una visión de derrota entre el pueblo, lo cual se vio reforzado por la situación económica que la Federación de Rusia heredó de los empréstitos realizados por la URSS.

De acuerdo con Graciela Zubelzú (2008), la identidad de los rusos ha estado marcada a través de su historia por tres elementos: el excepcionalismo, el mesianismo y el externalismo. Estos elementos se experimentan de forma particular en la autopercepción de los pueblos generando sentimientos específicos con respecto a los otros, así el comportamiento en la política exterior estará marcado en términos defensivos u ofensivos bajo esa percepción. Por ejemplo, la actuación de Rusia frente a su extranjero próximo ha sido ofensiva y marcada por una defensa férrea de lo que ha considerado durante siglos como propio, un sentimiento de excepcionalismo bajo el cual el pueblo ruso está destinado a influir en los pueblos eslavos; ${ }^{14}$ situación que se demuestra en la absorción de unidades territoriales por parte de la URSS como Bielorrusia y Ucrania, al igual que su influencia en los países de Europa del Este expandiéndose inclusive con la anexión de los países bálticos durante la Segunda Guerra Mundial.

El excepcionalismo convertido de ruso a soviético se vio reforzado con la exportación de la revolución comunista a otros Estados fuera de Europa, en especial por la estructura bipolar durante la Guerra Fría. El apoyo a las fuerzas insurgentes en latitudes transhemisféricas fue congruente con esta idea, la relación de la URSS y el PCUS con movimientos sociales comunistas y grupos beligerantes se concibió como necesaria desde la óptica casi misional con la que se pretendió establecer estos vínculos. Si se recuerda el período de Brézhnev, y la proclamación de su doctrina de intervención en los países del Este a través de Pacto de Varsovia, la cual fue expresada en términos de "ayuda mutua" entre los países miembros, fue una clara demostración del excepcionalismo soviético destinado a conducir la emancipación de los pueblos de la explotación capitalista (CIDOB, 2010).

La disolución del período de distensión se explica, en parte, por el comportamiento de ambas potencias: la guerra de Vietnam, la invasión soviética en Afganistán, la Iniciativa de Defensa Estratégica proclamada por Reagan, entre otros aspectos que ya se abordaron en los acápites anteriores, son una muestra del papel que jugó la idea manifiesta de una identidad excepcionalista. Estas manifestaciones han ido acompañadas con el sentimiento generalizado que los rusos no son sencillos de entender, que su sociedad es prácticamente enigmática, y que, por lo tanto, no serán entendidos por los no rusos. Sin embargo, esto se vio interrumpido durante la reestructuración planteada por Gorbachov en la Glasnot seguido por el desmembramiento de la URSS (Zubelzú, 2008).

En consecuencia, con la desintegración de la URSS y la reducción del territorio soviético, la excepcionalidad como elemento identitario para los rusos perdió espacio y el externalismo como tal cobró mayor auge ante la crisis económica y política que acompañó a la Federación de Rusia en la posguerra fría. El externalismo comprende la propensión de una población a percibirse como víctima de situaciones y actores externos (Zubelzú, 2008, pág. 129). En cierta forma, este sentimiento explicaría el rechazo a las medidas prooccidentales de Yeltsin en materia de política exterior los primeros años de su mandato en los que se legitimó la unipolaridad del sistema, inclusive permitiendo la ampliación de la OTAN a los países de Europa del Este (Marquez Díaz, 2014).

Las intervenciones de los Estados Unidos durante la posguerra fría fue para los rusos una muestra que la unipolaridad blanda en la que habían creído no era real. En ese sentido, los movimientos que se establecieron a través de la OTAN, como la intervención en los Balcanes y el 
problema kosovar despertaron en Rusia sentimientos de desconfianza hacia Occidente. La entrada de países a la OTAN como Polonia, Hungría y República Checa en 1999 agravaron este sentimiento de externalidad: se sintieron engañados por el incumplimiento de la promesa hecha a Gorbachov de no expandir la organización más allá de la recién unificada Alemania. Los siguientes sucesos ya en los inicios del siglo XXI como las Revoluciones de Colores y la siguiente ampliación OTAN en 2004 fijaron totalmente la legitimación de una política exterior más asertiva, la cual se venía construyendo desde el impulso de las relaciones diplomáticas y económicas con países emergentes en la búsqueda de una estructura multipolar. Así Rusia reemergía como potencia global, ${ }^{15}$ tomando ventaja de las relaciones comerciales mediante la venta de hidrocarburos, energía y exportación de armamento a nivel mundial.

Con estos antecedentes, el posicionamiento de Rusia responde en cierta medida a la necesidad de obtener el reconocimiento como tal por Occidente, en una apuesta por la disuasión constante en sus espacios de interés estratégico, lo cual se evidencia a través de los conflictos congelados que mantiene en la región euroasiática, cuyo statu quo es conveniente para continuar con su presencia, como el caso de Osetia del Sur, Abjasia y Crimea, por mencionar algunos (Álvarez Portas, 2020). En otro aspecto, Rusia aprovecha generar un arraigo identitario constante a través de las raíces lingüísticas y cristianas ortodoxas con las minorías rusas presentes en la zona ex soviética, lo que le ha dado réditos políticos importantes con los países ex URSS, en especial los de la zona de Asia Central con quienes inclusive ha signado acuerdos migratorios y mantiene alianzas militares destacables a través de la OTSC (De la Gandara Frieyro, 2018).

Por otra parte, así como en la época de los zares, el papel de la Iglesia Ortodoxa Rusa está tomando auge en la legitimación de las políticas del Estado reforzando los valores y creencias ortodoxas como parte inseparable de la identidad étnica rusa. En este punto, puede representarse el elemento de mesianismo partiendo del papel que ha jugado la Iglesia en el reforzamiento de sentimientos nacionalistas y su acercamiento al Estado le diferencian de las concepciones occidentales de las instituciones religiosas. La aceptación de la Iglesia y sus creencias como una especie de renacimiento religioso se ubican en dos hitos identificables: el primero durante el período de la Perestroika cuando en 1988 se reconoce como festival nacional la conmemoración del Bautismo de Rusia; ${ }^{16}$ el segundo, se registró en 1999 cuando, después de la dimisión de Yeltsin, Vladimir Putin pidió la bendición del Patriarca Alexy II para iniciar su mandato interino, cuestión que se consideró de lo más natural para un líder político ruso (Cabeza, 2008).

Durante los mandatos de Vladimir Putin no ha sido extraño la consulta frecuente al clero ortodoxo, esto, según el mismo presidente, por considerar a la Iglesia Ortodoxa como una institución que preserva los valores y la identidad de la sociedad rusa. Aunque constitucionalmente el Estado ruso se define como laico, las expresiones de apoyo mutuas han sido constantes, por ejemplo, en 2016 el presidente ruso inauguró una estatua de 11 metros de alto del Príncipe Vladimir, considerado santo por la Iglesia Ortodoxa; en su discurso Putin llamó a imitar el legado espiritual del santo. Aunque las críticas sobre el papel histórico del príncipe han puesto en tela de juicio la pertinencia del monumento y han esbozado algunas razones propagandísticas para la colocación de la estatua, esta ha sido una confirmación de la buena relación de la Iglesia con el gobierno (BBC Mundo, 2016).

La Iglesia Ortodoxa también influye en el comportamiento externo de Rusia, de hecho, fortalece el ideario mesiánico de la nación al exacerbar los valores materiales y espirituales propios de Rusia, lo que consideran como causas justificantes de un lugar importante en el orden mundial que debe 
ser sostenido enfrentándose a los recursos con los que cuenta occidente en términos financieros. En ese orden de ideas, la Iglesia utiliza el vocablo de russkie (ruso étnico) para referirse al pueblo, sin importar si estos practican la fe ortodoxa o no, partiendo de una concepción religiosa-étnica, puesto que no se hace distinción en los mismos términos que la cristiandad occidental, donde la práctica religiosa no tiene relación directa con la etnia. Inclusive algunas políticas impulsadas por el Kremlin son tendientes a mantener alejada la influencia de otras religiones en el país, ${ }^{17}$ así a través de sus discursos y prácticas religiosas ortodoxas el mismo presidente remarca la preeminencia de la cristiandad como religión originaria e identitaria del pueblo ruso (Cabeza, 2008, pág. 136).

La identidad rusa está compuesta por una serie de factores históricos que han reforzado los elementos identitarios expuestos brevemente en estas líneas, razones por las que la posición asertiva de Rusia en su política exterior es legitimada por los sentimientos de excepcionalidad y externalidad principalmente. La situación de crisis económica en la década de los noventa, la ampliación de la OTAN y la relación comercial de la Unión Europea con países ex soviéticos como Ucrania, han reafirmado las ideas sobre Occidente y su pretensión por reducir el poderío ruso. La visión estatal de Vladimir Putin con una política exterior diversa basada en la doctrina Primakov, no es más que un reflejo de los factores identitarios que han caracterizado a Rusia a través del tiempo y condensados en la concepción del nacionalismo ruso que ha permitido la creación de un Estado fuerte que responde a la idiosincrasia del pueblo ruso y que ha sabido explotar el patriotismo y sus manifestaciones históricas para generar una disciplina nacional.

\section{CARACTERÍSTICAS GEOPOLÍTICAS DE AMÉRICA LATINA}

En este apartado se abordarán las características de América Latina como un todo, las cuales le convierten en un escenario estratégico para las potencias multipolares. Sin ánimos de generar un vacío de información, no se abordarán en este apartado datos geográficos de la región o datos específicos por país; lo que se pretende es crear un marco de referencia empírica que permita la comprensión de los factores que determinan el interés ruso en la región y sus manifestaciones a través de la acción exterior concretada en acuerdos y relaciones económicas en su mayoría.

\subsection{El ideario geopolítico de América Latina: la doctrina Monroe y relaciones multipolares}

Al hacer un esbozo sobre las características geopolíticas de América Latina es inevitable hablar de la relación de la región con los Estados Unidos a través de la historia. Así, la Doctrina Monroe ha sido la base bajo la cual los estadounidenses han establecido influencia y dominio directo sobre la región desde tiempos decimonónicos y que siguen siendo espacios de importancia para su seguridad nacional considerando a toda Latinoamérica como su frontera sur (Sánchez de Rojas Díaz, 2016). La existencia de Estados vastos y con recursos extractivos importantes en América Latina fue considerada por los Estados Unidos como un flanco a cubrir, ${ }^{18}$ puesto que se pensó sobre la posibilidad que tendrían de unir esfuerzos para hacer frente a la influencia estadounidense y adoptar un papel más proactivo dentro de la región.

Esta preocupación fue sistematizada por Nicholas Spykman y dividió América Latina en dos subregiones llamadas América Mediterránea y Sur América, la primera estaría compuesta por 
México, Centro América, el Caribe, Colombia y Venezuela; mientras que la segunda simplemente comprendería los países restantes. América Latina siempre ha sido importante para Estados Unidos como primera línea de seguridad y el espacio fértil para las inversiones y mano de obra barata a través del flujo constante de migrantes (Sánchez de Rojas Díaz, 2016). Se considera que a 2019 los latinoamericanos en suelo estadounidense suman un poco más de 31 millones de personas. Para 1910 las mayorías inmigrantes en EE. UU. eran de origen europeo, asiáticas y latinoamericanas, las cuales estaban bastante marcadas en los Estados de destino de acuerdo a las capacidades laborales de estas poblaciones; sin embargo, más de un siglo después, las migraciones latinoamericanas se han dispersado en todo el país y solamente en territorios como Alaska y Hawaii no constituyen poblaciones representativas (EOM, 2018).

En todo el siglo XX, la historia latinoamericana ha estado marcada por una relación directa con su vecino del norte, e inclusive ha transitado por los mismos estadios políticos que han sido convenientes para los intereses norteamericanos, así podría hablarse después de la Segunda Guerra Mundial y la doctrina de contención de los Estados Unidos frente al comunismo, la que estuvo marcada con mayor fuerza en el continente, de forma que los lazos económicos y de "cooperación" se fueron moviendo con intenciones claras de no permitir la intrusión de la influencia de la URSS. Por ejemplo, los procesos de integración establecidos por la CEPAL ${ }^{19}$ en América Latina y las políticas de sustitución de importaciones fueron en varios casos saboteadas por la Agencia de Cooperación Estadounidense (USAID), esto porque tales propuestas fueron consideradas en su momento comunistas. Como contrapeso, la agencia de cooperación logró que los Estados se desentendieran de las reformas propuestas por la CEPAL a través de promesas traducidas en ayudas económicas mayores que las pretendidas por el organismo, de esa manera incidieron en algunos proyectos importantes como la consolidación del Mercado Común Centroamericano (Carreras, 1997)

Más adelante, con el triunfo de la revolución cubana y la influencia de la URSS en América Latina, los estadounidenses comprendieron la importancia de reforzar sus espacios de cooptación en la región para mantener el "Perímetro de Seguridad" ya mencionado por Spykman en su momento. Reconociendo el peligro estratégico que representó Cuba después de la Crisis de los Misiles en 1962; la situación de acabar con el enemigo "interno" se volvió imperativa. En tal sentido, la Doctrina de Seguridad Nacional estadounidense se apoyó en las fuerzas armadas latinoamericanas para terminar con los intentos de revolución comunista en el continente y fortalecer las dictaduras militares que le fueron convenientes (Sánchez de Rojas Díaz, 2016).

Durante los 80's y con el fin de la distensión entre la URSS y EE. UU., Latinoamérica jugó un papel elemental para generar espacios de negociación en la región Centroamericana, afectada en esa década por 3 conflictos armados: la contrarrevolución nicaragüense y los conflictos civiles de El Salvador y Guatemala. Así, en un proceso de anti- geopolítica, ${ }^{20}$ los cancilleres de Colombia, México, Panamá y Venezuela iniciaron en 1983 la negociación entre las partes involucradas en los conflictos centroamericanos, bajo el nombre de Grupo de Contadora, en atención a la ciudad panameña donde se llevaron a cabo las primeras reuniones. Lo importante de este grupo latinoamericano de plenipotenciarios residió en la capacidad de denunciar la injerencia constante de fuerzas extranjeras en los conflictos armados, es decir, los Estados Unidos y la Unión Soviética, con mayor énfasis en los norteamericanos, en especial por la Iniciativa de Seguridad Estratégica de Reagan que reforzó las acciones antisubversivas en la región y envió asesores militares que prepararan a las 
fuerzas armadas centroamericanas y a la contra nicaragüense para hacer frente a los movimientos sociales y fuerzas beligerantes en El Salvador y Guatemala.

Reagan consideró a Centroamérica como la cuarta frontera estadounidense y solicitó al Congreso fondos por 110 millones de dólares en ayuda militar para El Salvador en 1983 considerando que era importante terminar con la guerrilla salvadoreña que estaba siendo patrocinada por Cuba, Nicaragua y la URSS. Así el panorama los miembros de Contadora tuvieron que cuidar mucho de sus posiciones frente a la política exterior estadounidense a fin de marcar una crítica y denuncia constante de la situación en Centroamérica, pero sin tener incidentes diplomáticos con los EE. UU. (Paez Montalbán, 2013)

Con la posguerra fría y la amenaza comunista desaparecida, América Latina continuó siendo prioridad como espacio geopolítico y de interés económico para los norteamericanos, la liberalización de las economías y la privatización de las empresas estatales fueron parte de las medidas impulsadas en la región a través de los organismos financieros multilaterales con preponderancia estadounidense como el FMI. Se argumentó bajo el paradigma de la globalización y de la crisis del Estado la necesidad urgente de dinamizar las economías a través del libre comercio y la apertura de los Estados a tratados bilaterales y multilaterales para lograr el crecimiento económico.

La propuesta que marcaría el culmen de esta apertura sería la creación del Área de Libre Comercio de las Américas (ALCA), iniciativa que pretendía crear una zona de libre comercio desde Alaska hasta La Patagonia. El ALCA sería la consolidación del poder comercial y financiero de los Estados Unidos; no obstante, por lo ambicioso del proyecto, los norteamericanos decidieron iniciar el proceso de liberalización por partes. En 1994 firmaron el Tratado de Libre Comercio de América del Norte (TLCAN) que incluye a Canadá, Estados Unidos y México. Este tratado fue denunciado por las minorías indígenas mexicanas, en especial por los miembros del Ejército Zapatista de Liberación Nacional, considerado lesivo para las poblaciones indígenas porque generó mayor exclusión y pobreza debido a la expropiación de tierras en favor de multinacionales y la importación de materias agrícolas estadounidenses frente a la producción local (Badine El Yattioui, 2019/2020).

A inicios del siglo XXI, Estados Unidos negoció un Tratado de Libre Comercio con Centroamérica como bloque, conocido como CAFTA por sus siglas en inglés, ratificado entre finales de 2003 e inicios de 2004, al que se adhirió República Dominicana en julio de 2004, recibiendo el nombre de DR-CAFTA (CEPAL Subsede México, 2007).

Aunque el proceso de ALCA se ha visto comprometido en los últimos años debido al surgimiento de procesos alternativos de libre comercio con alcances regionales, América Latina ha optado por procesos de regionalización y el establecimiento de relaciones comerciales entre estas o con otros Estados extra hemisféricos a sabiendas del importante espacio geopolítico que representan en conjunto: la producción de commodities desde mercancías agrícolas, minerales como cobre e hidrocarburos hasta su posición estratégica como vecinos de una de las potencias globales como Estados Unidos.

\subsection{Los procesos de integración regional en América Latina como una propuesta alternativa}

Desde la época anterior a la caída del bloque soviético, los países latinoamericanos han llevado a cabo procesos de integración regional como medio para lograr mejores indicadores económicos 
y fortalecer las relaciones políticas entre los Estados vecinos. Algunos de estos esfuerzos datan de mediados del siglo XX como: el Mercado Común Centroamericano (MCCA) de 1960, la Comunidad Andina de Naciones (CAN) creada en 1969 y la Comunidad del Caribe (CARICOM) de 1973, por mencionar algunos. Estos tenían como objetivo común generar crecimiento económico a través del estrechamiento de los lazos comerciales en la región logrando condiciones arancelarias favorables entre sus miembros, así como atraer inversiones directas de otros países (RIJIA, 2012). Estas regionalizaciones surgieron durante el esquema bipolar y no fue mucho del agrado de los Estados Unidos, quienes veían en estos organismos una amenaza que podría disminuir su capacidad de influencia en Latinoamérica; no obstante, se siguieron manteniendo y algunos de estos lograron amplificarse con el paso del tiempo y convertirse en sistemas de integración regional más complejos.

Durante el período de la posguerra fría y la implantación de medidas neoliberales y de libre comercio a nivel continental, los procesos de regionalización se diversificaron y crearon tendencia como vía para el desarrollo económico. Estos procesos requirieron de mayor autonomía por los Estados parte, desligándose de influencias externas o dependiendo de los modelos dictados por economías más desarrolladas, en este caso los Estados Unidos. Entre estos procesos regionales de la posguerra fría se encuentra el Mercado Común del Sur (MERCOSUR), ${ }^{21}$ con características geopolíticas ventajosas ya que posee grandes reservas de petróleo, diversidad en flora y fauna, mantos acuíferos, también por su gran extensión de tierra cultivable son los mayores productores de alimentos en la región. Mientras los gobiernos de los Estados miembros estaban en la misma línea ideológica, el MERCOSUR impulsó negociaciones de libre comercio con otros países como Israel, Palestina y Egipto. Con el paso del tiempo y las diferencias entre estos por cuestiones ideológicas estacaron negociaciones con EE. UU. para un tratado de libre comercio, tema que no se volvió a tratar en el seno de la organización (Sánchez de Rojas Díaz, 2016).

Durante el mandato de Hugo Chávez en Venezuela se impulsó una serie de acciones exteriores tendientes a crear organizaciones multilaterales alternativas a los organismos establecidos con la presencia de Estados Unidos como líder, así se estableció la Alternativa Bolivariana para las Américas (ALBA) en contraposición al proyecto estadounidense del ALCA que había recibido cierto impulso por el gobierno de George Bush. Esta alternativa liderada por Venezuela aglutinó a varios países latinoamericanos con gobiernos de izquierda y, aunque algunos países no se adhirieron al $\mathrm{ALBA}^{22}$ sí lo hicieron con la iniciativa de Petrocaribe, ${ }^{23}$ la cual se lanzó con el objetivo de dinamizar la distribución del petróleo venezolano a los países de América Latina, así los Estados suscritos como beneficiarios pagan solamente el 60\% del precio de los hidrocarburos recibidos los primeros noventa días y el precio restante durante veinticinco años con un bajo interés, dejando una cantidad de fondos de la factura petrolera a los Estados receptores. Si algún Estado miembro tuviere problemas para pagar las cuotas establecidas, este puede hacerlo a través de intercambio de bienes y servicios (EOM, 2020).

Por otra parte, se crearon mecanismos multilaterales concretamente latinoamericanos en paralelo a la Organización de Estados Americanos (OEA) la cual cuenta con la participación de los Estados Unidos y Canadá; así surgió la Comunidad de Estados Latinoamericanos y Caribeños (CELAC) y otros esfuerzos de orden político más específicos como la Unión de Naciones Suramericanas (UNASUR). Estos organismos tuvieron su auge mientras la mayoría de los Estados miembros tenían gobiernos de izquierda en el poder. Actualmente, UNASUR y CELAC se encuentran 
estancados por el giro latinoamericano hacia gobiernos considerados de derecha en la última década.

Este tipo de acuerdos desafiaron la dependencia y alineamiento con los Estados Unidos ofreciendo los espacios para que otros Estados con economías emergentes trataran de establecer acercamientos más fuertes con la región como China y Rusia. Los objetivos de estas relaciones son variados de acuerdo con cada país, por ejemplo, para el caso de China las materias primas y los hidrocarburos latinoamericanos son importantes para su economía, al igual que las oportunidades de exportación de sus productos a un mercado significativo; en el caso de Rusia, el interés ha estado marcado por la ampliación de sus ventas de armamento e inversiones en el rubro energético. En ese mismo orden, los países latinoamericanos han visto estas posibilidades como alternativas de crecimiento económico en alianza con países que ofrecen otro tipo de capitalismo de Estado y en términos menos liberales, a diferencia de Estados Unidos (Serbín, 2018).

Ante todos estos movimientos de anti geopolítica, Estados Unidos respondió fortaleciendo los programas de comercio y seguridad que ya había establecido con México, a través de la Iniciativa Mérida; ${ }^{24}$ con Centroamérica mediante la Iniciativa Mesoamericana; ${ }^{25}$ la reactivación de la IV flota en el Atlántico Sur y la creación de siete nuevas bases militares en Colombia (Preciado Coronado, 2010). Simultáneamente, con la crisis humanitaria de niños inmigrantes irregulares sin acompañante en 2014 a raíz de la situación de violencia en los países más cercanos a su frontera sur, Estados Unidos fortaleció su relación con algunos Estados a los que consideraba aliados en la región centroamericana. Así, el vicepresidente Biden aprovechando la toma de posesión del electo presidente de Guatemala Jimmy Morales en 2016, se reunió con los presidentes del llamado “Triángulo Norte" ${ }^{26}$ con el objetivo de acordar el Plan Alianza para la Prosperidad ${ }^{27}$ propuesto por los países con mayor cantidad de inmigrantes irregulares en la región centroamericana (Banco Interamericano de Desarrollo, 2020).

Algo importante en este plan es que se enmarca en la Estrategia de Seguridad Regional (CARSI) ${ }^{28}$ liderada por los Estados Unidos, la cual responde a los intereses geopolíticos norteamericanos de generar control sobre la región dados los problemas de seguridad ciudadana en Centroamérica a consecuencia del crimen organizado y el traspaso de droga provenientes de Suramérica hacia México para llegar finalmente a los países del norte.

Los fondos norteamericanos de Alianza para la Prosperidad son dados a los países centroamericanos bajo cierta condición: si los ejes y líneas de acción establecidos en el marco del acuerdo cumplen los términos de referencia indicados los fondos son liberados, en caso contrario, estos son retenidos. Esta situación sucedió en Honduras y Guatemala en 2018 con la administración Trump, cuando las tasas de inmigrantes irregulares se incrementaron hacia los Estados Unidos (Criterio hn, 2018).

Actualmente, los organismos multilaterales que surgieron como alternativos a los foros ya existentes se han quedado estancados, no obstante, los Estados han redefinido estas alianzas de forma más orgánica con la participación de las minorías y la sociedad civil como propuesta diversificadora latinoamericana (Preciado Coronado, 2010). Por otra parte, aunque la mayoría de los gobiernos latinoamericanos son de derecha, las relaciones establecidas con China y Rusia se mantienen, con la diferencia que no poseen el mismo dinamismo que con los gobiernos de izquierda en especial con América del Sur. 


\section{LAS RELACIONES DE RUSIA Y AMÉRICA LATINA: DE LA URSS A LA FEDERACIÓN DE RUSIA}

Los lazos entre Rusia y algunos países latinoamericanos no es nada nuevo, las relaciones diplomáticas y comerciales con países latinoamericanos se establecieron en su mayoría durante la Segunda Guerra Mundial. Sin embargo, la Guerra Fría entre los Estados Unidos y la URSS condicionaron la profundidad de los lazos soviéticos en la región, no solo por la situación ideológica, sino que la URSS entendía que la zona era de influencia netamente norteamericana con mayores ventajas logísticas y geoestratégicas de las que los soviéticos pudieron pretender. Los países latinoamericanos vieron las relaciones con la Unión Soviética como una muestra de independencia y por otra parte una válvula de escape del alineamiento con los norteamericanos en la contienda bipolar (Blasier \& Vacs, 1983).

Las relaciones establecidas con la URSS en la época de la Guerra Fría se delimitaron a nivel estatal y la relación meramente política con la región estuvo establecida por el PCUS. Después de la revolución cubana, la cooperación entre los partidos comunistas de la región y el PCUS experimentaron un empuje; lo que llegó a ser hasta cierto punto contradictorio con las políticas impulsadas por el gobierno soviético, en especial durante el tiempo de la distensión. El tema de las ayudas y cooperación para Cuba y Nicaragua fueron un tema difícil en la administración de Gorbachov teniendo en cuenta su búsqueda por apoyo occidental. Tal como se explicó en títulos anteriores, Cuba recibió apoyo de la URSS hasta su desintegración a inicios de los noventa, a pesar de que representaba un problema para su economía ya bastante maltrecha.

Con el desmembramiento de la URSS y la emergencia de la Federación de Rusia, las relaciones comerciales con América Latina se mantuvieron, sin embargo, perdieron el protagonismo ganado en décadas anteriores y se ubicaron al margen tanto político como económico, lo que resulta coherente con la política exterior prooccidental establecida por Yeltsin, y, por otra parte a sabiendas que Latinoamérica era, a final de cuentas, un espacio afianzado por los Estados Unidos a través del neoliberalismo y los gobiernos de corte liberal en la región (Schuster, 2017). Dado el contexto internacional de la unipolaridad, el comportamiento ruso a nivel global se mostró defensivo excepto en su extranjero próximo, donde dejó clara su posición de liderar la CEI y en consecuencia a los países ex soviéticos continuando así con su dominio en la zona.

Con una política global basada en la Doctrina Primakov, Rusia se dirige a mostrarse más activa en la región latinoamericana en observancia a la emergencia de los gobiernos de izquierda en la mayoría de los Estados, los cuales establecieron una política exterior independiente de la influencia estadounidense y con ello generaron espacios de acercamiento diplomático, político y comercial, no solo con Rusia sino también con los llamados países emergentes como China y la India. En ese orden de ideas, en este apartado se hará un recorrido sobre las relaciones de Rusia y América Latina a través del tiempo, partiendo desde la URSS hasta la actualidad a fin de describir los principales puntos de concordancia e interés ruso en la región latinoamericana.

\subsection{Las relaciones de América Latina con la URSS}

La revolución bolchevique durante la Primera Guerra Mundial no fue bien vista por las potencias vencedoras de este conflicto, tal situación lo demuestra la negativa de los Estados miembros 
para aceptar a la recién emergida Unión de Repúblicas Socialistas Soviéticas en la Sociedad de Naciones por considerarla desestabilizadora en el orden internacional forjado en Versalles. Las afirmaciones de la exportación de la revolución y el proletariado internacional condicionaron las relaciones diplomáticas de esta con otros Estados. En el caso latinoamericano, la URSS estableció relaciones diplomáticas solamente con México en 1924 y Uruguay en 1926. Esto también estaba determinado por la idea de varios países latinoamericanos, quienes estimaron que al establecer relaciones diplomáticas con la URSS los partidos comunistas internos podrían verse fortalecidos. En ese sentido, algunas desavenencias con el gobierno mexicano por las pretensiones de los partidos comunistas latinoamericanos llevaron al rompimiento de relaciones diplomáticas en 1930 (Varas, 1981).

No obstante años después, durante la Segunda Guerra Mundial varios países latinoamericanos establecieron relaciones diplomáticas con la URSS: Argentina, Brasil, Chile, Colombia, México (las retomó en 1942), Uruguay y Venezuela; en el caso de Bolivia, Costa Rica y Nicaragua, las relaciones diplomáticas fueron establecidas, aunque sin intercambiar funcionarios. Con la doctrina de contención establecida en el hemisferio occidental hacia 1947, América Latina se alineó en favor de los Estados Unidos con el Tratado Interamericano de Asistencia Recíproca conocido como TIAR en el mismo año y por medio de su pertenencia a la Organización de Estados Americanos (OEA) en 1948, cuestión por la que, varios países suspendieron los vínculos establecidos con la URSS (Varas, 1981, pág. 7).

Partiendo del proceso de desestalinización en la URSS y la desescalada de tensiones con los Estados Unidos, la región latinoamericana dejó de verse como una extensión de los estadounidenses y se revaloró como una zona de interés para el comercio y el establecimiento de relaciones diplomáticas y culturales, con la prudencia de no inmiscuirse en asuntos domésticos, dado que en el proceso de coexistencia pacífica se reconocía la influencia y dominio norteamericanos en aras de evitar las confrontaciones vividas durante el período de contención en el tiempo de Stalin (Blasier \& Vacs, 1983, pág. 200).

Las relaciones entre la Unión Soviética y América Latina fueron retomadas durante el mandato de Kruschev bajo la premisa de buscar mercados para sus productos y ofrecer una alternativa como destino de las exportaciones de materias primas y mercancías extractivas, de esa forma, estos países en desarrollo generarían independencia de los Estados Unidos al diversificar sus compradores y con ello un poco más de autonomía como región. Como era de esperarse, la revolución cubana en 1959 y el apoyo de los soviéticos al régimen de Fidel Castro supuso una situación difícil para las relaciones soviéticas- latinoamericanas; sin embargo, los soviéticos supieron manejar la situación a través de la distensión establecida por las potencias en la década de los sesenta después de la crisis de los misiles cubanos de 1962 (Varas, 1981, pág. 13).

En ese sentido, se priorizaron las relaciones comerciales sobre las políticas, aunque ello no fue impedimento para que la URSS a través de PCUS tuviera relación con los partidos comunistas de la región. Esta relación tuvo dos matices importantes: la URSS apoyó la vía pacífica y democrática para la llegada al poder en aquellos países donde la participación plural incluidos los partidos de izquierda estaba permitida y las condiciones para una insurgencia armada eran bastante escasas, muestra de ello fue la ascensión de Allende a la presidencia de Chile $^{29}$; por otra parte, a través del PCUS se apoyó directamente a movimientos insurgentes fuertes en aquellos países donde la propensión al conflicto armado era inminente para derrocar gobiernos dictatoriales, tal es el caso 
de Nicaragua en la década de los setentas y El Salvador una década después, en ambas ocasiones a través de la logística cubana.

En materia comercial, América Latina se vio beneficiada al llegar a acuerdos bilaterales y trilaterales que incluían países del CAME, ${ }^{30}$ con el auge en la década de 1970, las importaciones desde la región registradas en esos 10 años ascendieron cerca de los 5.37 mil millones de rublos mientras que las exportaciones de la URSS solamente se registraron en 838 millones (Blasier \& Vacs, 1983, pág. 204). Estas importaciones se concentraron en Argentina, Brasil, Bolivia, Perú y Uruguay quienes exportaban materias primas, metales no ferrosos y productos cárnicos. Hacia 1985 las importaciones se elevaron a 2.2 mil millones de rublos solamente para la URSS fuera del espectro del CAME, situación que representó un alivio para las economías latinoamericanas las cuales estaban pasando por una crisis debido al problema de la deuda y los bajos precios de las materias primas (Berríos, 1990). La asistencia técnica y la cooperación dada por la URSS a Latinoamérica fue provechosa, por ejemplo, Argentina, Brasil y Bolivia acompañaron esta asistencia con la compra de equipo soviético para desarrollar sus proyectos hidroeléctricos y centrales termoeléctricas (Blasier \& Vacs, 1983, pág. 206), este tipo de asistencia se mantuvo al menos hasta el derrumbamiento de la URSS a inicios de los noventa.

\subsection{Las relaciones de la Federación de Rusia y América Latina}

A diferencia de las relaciones entre la URSS y América Latina, la Federación de Rusia se mostró aislada con la región y se dedicó a continuar con las relaciones comerciales que heredó de los soviéticos sin mostrar proactividad por intervenir en el campo político, al menos en los primeros años de la década de los 90's. Los rubros de las exportaciones de América Latina hacia la Federación de Rusia y otros países de Europa del Este versaron siempre sobre materias primas y bienes semi manufacturados, mientras que las importaciones desde Rusia consistieron en su mayoría en materiales de acero laminado y productos energéticos. Las reformas económicas implementadas en los Estados resultantes de la disolución de la URSS para convertirse en economías de mercado trajeron como consecuencia procesos de privatización y liberalización de precios que dieron como resultado marcadas diferencias entre ricos y pobres.

Durante los años de 1992 a 1998, Rusia experimentó muy buenos indicadores en su balanza comercial en tanto que sus importaciones fueron menores a lo exportado en ese período. Con respecto al comercio con la región latinoamericana, Rusia logró un repunte en sus exportaciones hacia la zona, así en 1998 se registró promedio de 531.5 millones de dólares en mercancías destinadas al menos para los Estados miembros de ALADI. ${ }^{31}$ Los indicadores macroeconómicos rusos establecían un saldo positivo en sus exportaciones con 900 millones de dólares registrados entre 1994 y 1999 hacia la región latinoamericana, algunas de ellas a territorios de ultramar como las Islas Vírgenes Británicas, las Bahamas y la zona "offshore" de Panamá, aunque ello no significó reciprocidad en las importaciones de estos territorios desde Rusia, de hecho estos indicadores fueron ínfimos. En cuanto a las exportaciones rusas hacia América Latina, estas se concentraron en Brasil 41\%, México 16\%, Argentina 9\%, Colombia 9\% y Chile 4\% (Kouzmine, 2001, pág. 16).

En los años posteriores y con Primakov a la cabeza de la política exterior del país ex soviético, la Federación retomó las relaciones diplomáticas con América Latina y en 1997 el canciller ruso realizó una gira hacia la región. En una conferencia ante el Consejo Argentino para las Relaciones Internacionales, Primakov manifestó la importancia de América Latina y su desarrollo 
para Rusia, lo cual tiene completa coherencia con la búsqueda de nuevos mercados y países amigos en la pretensión de una multipolaridad (Sheykina, 2010). La idea de una Rusia pujante y caracterizada como potencia a nivel mundial incluía la influencia de la Federación en territorios transhemisféricos, y, habida cuenta de las buenas relaciones comerciales que sostuvo con América Latina en la época de la Guerra Fría, la oportunidad de recuperar estos lazos era decisiva.

Pese a lo anterior, la década de los noventa sostenía dos condiciones desfavorables para el reemergencia de Rusia en la zona latinoamericana: por una parte, las debilidades que en diferentes ámbitos el país venía presentando, entre ellas la desintegración del territorio, la pérdida de identidad y los problemas de desigualdad social y por otro, la relación con Estados Unidos en la zona latinoamericana, la cual debía estar amparada en términos que reconocieran no solo la unipolaridad del sistema, sino también la primacía de los estadounidenses en su frontera sur. Con este contexto como marco, Rusia se comporta bajo un realismo defensivo, buscando las relaciones con América Latina en los términos comerciales bajo parámetros liberales de acuerdo con el nuevo sistema unipolar. Así las cosas, fue hasta el ascenso de Vladimir Putin al poder de la Federación de Rusia con una política exterior más asertiva y global que América Latina se convierte en un espacio de ruptura de la estructura internacional.

\subsection{Las relaciones de Rusia y América Latina en el siglo XXI}

En el año 2000, Rusia comienza a reemerger como potencia mundial a través de una política exterior más asertiva en aras de obtener un mejor posicionamiento a nivel internacional que le permitiera tener el reconocimiento como potencia global en un sistema multipolar. En consecuencia, la relación de Rusia en América Latina ya considerada importante para los rusos desde la administración Yeltsin, se benefició de la llegada de partidos de izquierda a varios países latinoamericanos, entre ellos Argentina, Bolivia, Brasil y Venezuela. Con los acercamientos a países latinoamericanos, Rusia logró ampliar su cuota de mercado para la región por medio de la venta de armamentos a varios países, entre los que sobresalen Venezuela, Brasil, Colombia, México, Perú y Cuba con quienes tiene importantes contratos en esta materia y en 2008 entabló oportunidades de negocios con Chile, Uruguay y Ecuador (Garay Vera, 2010, pág. 165).

La posición privilegiada de Estados Unidos en la región cultivada tras la caída de la URSS comienza a desvanecerse a causa de la Doctrina Bush con una clara propensión al combate de los grupos considerados terroristas ubicados en Oriente Medio y por la emergencia de una posición más autónoma de América Latina propugnada por los gobiernos de izquierda que constituyeron mayoría y que propiciaron un escenario ideal para el acercamiento más asertivo de Rusia hacia Latinoamérica en el contexto de su reemergencia global.

La apertura comercial de los países latinoamericanos en este rubro abrió a su vez las posibilidades de relaciones más estrechas que incluyó en ciertos países ejercicios militares, este fue el caso de las maniobras militares entre Moscú y Caracas en 2008 frente a las costas venezolanas con un significado más simbólico que efectivo, partiendo que el armamento de las fuerzas armadas de Venezuela son en su mayoría estadounidenses, así el presidente Chávez siguió manteniendo su posición mediática “antiimperialista” y Rusia por su parte presentó sus intenciones de consolidarse como potencia global (Vinagre, 2008).

En ese mismo año, el presidente ruso Dimitri Medvedev realizó una gira por algunos países latinoamericanos entre ellos Brasil, Cuba y Perú, en este último asistió a la Cumbre Asia-Pacífico 
en la que declaró que Rusia había colocado como prioridad las relaciones con América Latina, así, Medvedev suscribió en Lima un acuerdo para la reparación de unos aviones peruanos de fabricación soviética. En Brasil, se establecieron acuerdos de profundización de asistencia técnica en materia militar y desarrollo espacial, también se incluyeron iniciativas económicas como la creación de empresas ruso- brasileñas y la realización de inversiones mutuas en rubros que estimaran convenientes. La gira del presidente ruso no terminó con los países mencionados, sino que la delegación viajó a Caracas en fechas que coincidió con los ejercicios militares entre las fuerzas armadas de ambos países (Deutsh Welle, 2008). Con esta gira realizada el mismo año que Rusia interviene en la guerra de Georgia, la Federación dejó en claro que sus intereses estaban apuntalados a lograr un resquebrajamiento de la estructura unipolar estadounidense y dar paso a través de su alianza con los países del BRICS ${ }^{32}$ a una multipolaridad.

Con las relaciones tensas entre Venezuela y Estados Unidos, Hugo Chávez reiteró sus ofrecimientos de una isla con aeródromo para que fuera utilizada como base aérea temporal de las fuerzas rusas. En ese mismo orden de hechos, en 2009 Rusia logró suscribir acuerdos con Bolivia en diferentes ámbitos inclusive la lucha antidrogas y una línea de crédito ventajosa para la renovación de armamentos (Garay Vera, 2010, pág. 161). Como Latinoamérica ofrece una posición geoestratégica importante entre el Atlántico y el Pacífico los intereses rusos se consolidaron no solo con obtener ventas significativas en armamento y retomar las relaciones diplomáticas, sino que permitió una ampliación de la distribución de influencia en la estructura internacional en especial por sumarse como observador en aquellos esfuerzos regionales de los que Estados Unidos no forma parte $^{33}$.

Aunque las relaciones comerciales entre Rusia y los países latinoamericanos hayan experimentado un acercamiento mayor al de la década anterior, la realidad es que las exportaciones de América Latina hacia la Federación, no son tan significativas si se comparan con los intercambios comerciales entre los países de la zona y otros Estados, por ejemplo los 12 mil millones de dólares producto del intercambio en 2012 solo representó el 3\% de la cantidad intercambiada en el comercio entre China y Latinoamérica (García, 2012), por lo que, la existencia de las relaciones entre Rusia y la región no están determinadas por la importancia en volumen del intercambio de mercancías dentro de ambos mercados, sino que radica en una relación simbiótica que resulta indispensable para la consolidación de los intereses globales de Rusia y la necesidad de una mayor autonomía para los Estados latinoamericanos.

En 2014, Vladimir Putin, electo como presidente de la Federación por segunda ocasión, realizó una gira a América Latina en la que visitó los países más emblemáticos en cuanto a las relaciones establecidas con su país como Cuba, Argentina y Brasil, en este último estuvo hospedado del 13 al 16 de julio en vista de diferentes compromisos que incluyeron desde la final de la Copa del Mundo, la sexta cumbre del grupo BRICS y su primer encuentro con el foro de países miembros de UNASUR; lo cual no es extraño siendo una perfecta válvula de escape ante las sanciones impuestas por occidente ante la situación ucraniana y otras expansiones de la influencia OTAN hacia regiones de Europa oriental, este acercamiento fue puntualizado por Víctor Mijares ${ }^{34}$ como más estratégico que ideológico dada la necesidad de Rusia de buscar apoyos transhemisféricos significativos en vez de aislarse como sucedió en la década de los 90's (Deustche Welle, 2014).

Rusia, buscó diversificar su presencia en diferentes países de Latinoamérica a los que consideró estratégicos, estableciendo 3 grupos distintos: Atlántico representado por Argentina y Brasil; Pacífico que incluye a Ecuador y Perú; y El Caribe con Cuba, Nicaragua y Venezuela. En el caso de 
Argentina, hay que apuntar que desde el establecimiento de relaciones comerciales con la URSS ha sacado muy buenos réditos de este lazo. En años recientes, durante los gobiernos de Cristina Fernández de Kirchner, hubo acercamientos importantes a nivel político con el apoyo recibido en foros multilaterales como el G20, la OMC y el Banco Mundial, así se posicionó entre los países emergentes más importantes de la región. Aunque el entusiasmo ha sido menor con los gobiernos de Mauricio Macri y Alberto Fernández las relaciones se mantienen a pesar de haber experimentado una recesión en 2016 (Sitenko, 2017).

Recientemente, las cifras de exportación de productos argentinos a Rusia se contabilizaron en 814 millones de dólares para 2019, a pesar de haberse contraído en un 3\% con respecto a 2018. La mayoría de los bienes exportados a la Federación corresponden a productos alimenticios entre ellos carne, frutas, pescados, entre otros (Cámara de Comercio e Industria Argentino Rusa, s.f.). Estos datos de intercambio entre Argentina y Rusia no son de extrañeza, la relación comercial e intercambio de productos alimenticios y materias primas fue ventajosa para los argentinos y aunque no son cifras voluminosas si corresponden a un buen mercado para estos.

Con Brasil y sus distintos gobiernos, las relaciones han sido muy buenas e inclusive Rusia se pronunció en contra de una posible injerencia extranjera en el proceso de impeachment en contra de Dilma Rousseff, no obstante después de su destitución, los rusos prefirieron mostrarse al margen y seguir las relaciones bilaterales con el gobierno de Michel Temer y su alianza en el foro BRICS (teleSUR, 2016). Las relaciones comerciales de Brasil y Rusia se han mantenido aunque no significa que desplacen a Estados Unidos o China como socios importantes, para 2018 el intercambio de mercancías entre ambos países rondaba los 5,000 millones de dólares, el 70\% de las exportaciones rusas representan productos para la producción agrícola, en específico en compra de abono de la empresa Phosagro (Sputnik News, 2019).

Con respecto a ciertos apoyos que el Kremlin ha dado a gobiernos considerados autoritarios en Latinoamérica como el de Daniel Ortega en Nicaragua, es importante destacar que este apoyo se ha traducido en una relación mercantil para la compra y equipamiento de nuevo armamento, por ejemplo, el gobierno nicaragüense en 2008 recibió de Rusia cerca de 200 millones de dólares solamente en equipo de defensa y esto sin contar el interés ruso en ese momento por la posible construcción de un aeropuerto de aviación civil situado en la costa atlántica (Sheykina, 2010). Esta situación puso en alerta a sus vecinos costarricenses, según lo expresado por Constantino Urcuyo reconocido analista político en ese país, afirmando que la presencia y cooperación rusa con Nicaragua representa un desbalance entre la región centroamericana y que este desequilibrio, en palabras del analista, constituye una agresión indirecta. Para Urcuyo, Costa Rica debería replantearse continuar las relaciones diplomáticas y comerciales con la Federación (Malamud, 2013). En términos pragmáticos, este apoyo estaría determinado por la posición radical antinorteamericana del gobierno de Ortega, oportunidad suficiente para que Rusia pueda influir en la región más cercana a los Estados Unidos.

Con lo anterior, es claro que todas estas acciones exteriores están concentradas en hacer ver a los Estados Unidos de América que es necesario su reconocimiento en el cambio de la estructura de poder, la cual se ha desplazado de la unipolaridad para incluir a otras potencias, transformándose en una estructura multipolar compartida entre varios Estados y de los cuales en términos geopolíticos podemos mencionar como líderes a una triada que incluye a China, Estados Unidos y Rusia (Rodríguez Hernández, 2019). La carrera entre estos actores no se ha detenido y ha mostrado comportamientos de realismo ofensivo por parte de Rusia al apoyar públicamente el gobierno de Nicolás Maduro en Venezuela, claro está que esto no es solamente por una conveniencia política sino 
también económica dadas las cifras de compra de armamento registradas durante la administración de Chávez y las inversiones en el tema de hidrocarburos a través de Gazprom Neft. ${ }^{35}$ En este rubro los rusos siguen explorando en la franja petrolera del Orinoco y la continuidad de este proyecto según los encargados dependerá de los datos que arroje esta exploración para evaluar la rentabilidad del proyecto y continuar con ello si las partes, que incluye a Petromiranda, ${ }^{36}$ así lo acuerdan (La Vanguardia, 2019).

Estas inversiones implican una relación importante en el largo plazo para los rusos, situación que beneficia a Venezuela como elemento disuasorio ante una posible intervención estadounidense en el país, esto, a raíz que Washington considerara las elecciones de 2018 como fraudulentas por una serie de denuncias de la oposición. En ese aspecto, Donald Trump manifestó en 2019 algunas intenciones sobre el país caribeño en el discurso del estado de la Unión y aunque no contempló la intervención militar si dejó claro continuar con las sanciones diplomáticas y económicas hacia Venezuela (Bermúdez, 2019). Claramente, este tipo de declaraciones han generado reacciones por parte del gobierno ruso, como consecuencia de que funcionarios del gabinete de Trump manifestaran que "Rusia pagará el precio" y que deben salir de Venezuela, esto por su apoyo al presidente Maduro. No obstante, en marzo de 2019, la respuesta de Rusia fue el envío de militares rusos a Caracas y con ellos equipamiento militar, cuestión que molestó a Estados Unidos (BBC Mundo, 2019).

La pandemia de la Covid 19 en 2020 con cifras que rondan el millón de fallecidos y más de 48 millones de contagiados, ${ }^{37}$ ha significado para Rusia otra oportunidad de presentarse como potencia global. Dada la necesidad de obtener una vacuna para su cura, varios laboratorios de distintos países ${ }^{38}$ se han sumergido en una carrera contra el tiempo para obtenerla, entre estos esfuerzos se encuentra Sputinik V, la vacuna propuesta por la Federación de Rusia para ensayos clínicos en humanos y con la que Rusia está dispuesta a admitir personas voluntarias de países latinoamericanos en sus pruebas. Aunque algunos científicos occidentales han dudado de su eficacia y establecido a su vez ciertas reservas sobre el proceso de investigación para la Sputnik V, no cabe duda que Rusia se ha mostrado ofensivo en este juego que algunos denominan la guerra geopolítica de las vacunas, en la que se asegura se extenderá la brecha de desigualdad entre los países que tienen las posibilidades de abastecerse con la vacuna cuando esté lista y aquellos que no puedan hacerlo (Alonso, 2020).

Así, Venezuela y México han firmado documentos catalogados como confidenciales para iniciar pruebas de la vacuna rusa en voluntarios nacionales, por otro lado, también se habla de la posibilidad que Brasil y Argentina puedan producirla al igual que laboratorios argentinos y nicaragüenses, pero a la fecha no se ha conocido un acuerdo formal (Wallace, 2020). En este contexto, es importante señalar que la situación latinoamericana con respecto a la mortalidad por la pandemia es apremiante, según estadísticas recientes, solo en la región se contabilizan cerca de 10 millones de infectados y 396,034 fallecidos (Statista, 2020). En consecuencia, el éxito de la vacuna rusa aliviaría los embates por los que la población de la zona está pasando, de esa forma, la influencia del país ex soviético en la región crecería significativamente pero sin igualarse a la de Estados Unidos, puesto que, a través de la posibilidad del envío en términos de compra o donación a los países más necesitados de la vacuna contra la COVID19, Rusia estaría en la capacidad de generar alianzas políticas con los países latinoamericanos en foros internacionales como la Asamblea de Naciones Unidas y los esfuerzos de integración regional en los que podría participar. 
Ante estos datos y otros escenarios posibles como el planteado en el párrafo anterior, es evidente de que Rusia ha reforzado las relaciones económicas y políticas en la región para consolidarse como potencia global reclamando una multipolaridad en la estructura internacional frente a los Estados Unidos.

\section{PERSPECTIVAS}

La evolución de la política exterior de Rusia después de la caída de la URSS ha estado determinada por las capacidades que ostenta de hacer frente a la estructura internacional en la que se encuentra, así por ejemplo, la posición pro occidental de Yeltsin obedeció a la necesidad de estabilizar el país a través de ganar la confianza de occidente para obtener beneficio de la cooperación y el establecimiento de alianzas con los países ex soviéticos en el marco de los esfuerzos regionales como la CEI y no quedar completamente relegada del nuevo escenario unipolar.

La aceptación del nuevo papel de los Estados Unidos como líder mundial frente a la "derrota" soviética condicionó los factores de identidad de la población rusa, generando sentimientos de externalidad más arraigados que durante la guerra fría, factor que incide para que las acciones consideradas agresivas por occidente se encuentren legitimadas como justas pretensiones dados los sentimientos de humillación experimentados durante el período de transición de la URSS a la Federación de Rusia. Así, los rusos que apoyan las gestiones del gobierno ven en sus presidente Vladimir Putin, un hombre fuerte y con determinación para hacer de Rusia una potencia global, cuestión que les ha llevado a manejar el realismo como base teórica para la consecución de sus objetivos con una modalidad en un inicio defensiva y de apoyo a los Estados Unidos en las intervenciones hacia Afganistán en el marco de la lucha contra el terrorismo pero que supo defender los intereses nacionales en el extranjero cuando se opuso a la invasión a Irak y se alió con otros países europeos.

El comportamiento realista ofensivo utilizado como modus operandi y premisa para presionar hacia un orden multipolar, el cual ha sido reforzado a través del uso de su pipeline diplomacy condicionando las relaciones diplomáticas y comerciales con países de Europa del Este, le ha permitido congelar conflictos importantes a su favor como el de Crimea, Osetia del Sur y Abjasia en la medida que el estancamiento de estos sigue representando una ventaja dominante en estos territorios que gozan del apoyo del Kremlin. Las sanciones impuestas por los miembros de la UE y Estados Unidos por la anexión de Crimea siguen poniendo a prueba a la economía rusa, sin embargo, la dependencia a las mercancías energéticas a precios favorables en el mercado ha llegado inclusive a que países como Alemania sigan dando su apoyo a iniciativas como Nord Stream 2 para optimizar la distribución de gas hacia el país.

Con la expansión de la OTAN hacia Europa del Este y a los países ex soviéticos, Rusia ha respondido con un comportamiento activo en las regiones que considera estratégicas y de dominio ruso por naturaleza como ha sucedido en la zona del enclave de Kaliningrado frente a los países miembros de la Organización atlantista, también ha ampliado sus pretensiones en el Ártico con una disputa con otros países ribereños por la jurisdicción de la Dorsal Lomonósov que extendería en consecuencia su plataforma continental, así como su apoyo al gobierno de Bashar Al Assad en Siria para mantener una de las bases militares geoestratégicas en torno al Mediterráneo como Tartús, la que le facilita mantener buques en mares cálidos al igual que sucede con la base de Sebastopol en el Mar Negro. Respecto a su extranjero próximo, Rusia fortaleció el Tratado de Seguridad Colectiva 
y dio el impulso para transformarle en la Organización del Tratado de Seguridad Colectiva que, aunque no se considera por parte de sus miembros como un contrapeso de la OTAN, establecieron esfuerzos para la creación de fuerzas de tarea conjunta en la región.

En ese mismo sentido, Rusia ha trabajado con otros países emergentes para ampliar su campo de acción de regional a global acompañando foros y organismos alternativos a los planteados por occidente, así es miembro del Banco Asiático de Inversión en Infraestructura y miembro del grupo BRICS que le permitió ser reconocido como una potencia emergente global. Las condiciones económicas favorables a raíz de los altos precios del petróleo le facilitaron inyectar capital a otras industrias rusas como la de armamentos, generando por medio de la innovación y desarrollo de productos la ampliación de sus mercados incluyendo países latinoamericanos con los que se había tenido relaciones comerciales "tibias" durante el mandato de Yeltsin con un leve entusiasmo en el período del canciller Primakov.

La relación de América Latina y Rusia ha sido aprovechada por Moscú no solo en términos comerciales y de inversión, sino también por la cercanía de la región con los Estados Unidos y su influencia hegemónica en la zona. Aunque no se igualan los lazos de los países latinoamericanos con Estados Unidos y la UE, lo que está a la vista es que Rusia no pretendería sustituir a las potencias occidentales dentro de la región, sin embargo, su comportamiento exterior indica que seguirá tomando ventaja de las oportunidades que los Estados ofrezcan en términos comerciales y diplomáticos para mostrar su presencia en la zona. Por lo que se ha observado durante el ejercicio de esta política exterior más diversa y multipolar, el modus operandi de la Federación de Rusia para crear nuevos espacios de influencia se inicia bajo esta modalidad: al principio a través de las relaciones meramente comerciales, al afianzar esta relación se hace un acompañamiento político de las acciones exteriores del Estado receptor y así se logran algunas concesiones en otros ámbitos como las inversiones y los medios de comunicación social, lo cual podría incluir visitas de mandatarios a Moscú para concretar estos aspectos.

Las visitas del presidente Medvedev y Putin a Latinoamérica han estado caracterizadas por giras presidenciales a varios países de la región y por su participación en foros regionales alternativos, cuestión que marca claramente la imagen de Rusia como una potencia emergente y electiva en la construcción de una estructura multipolar dispuesta a apoyar los esfuerzos por generar mayor autonomía e independencia de la influencia estadounidense. En contraste, la administración de Donald Trump se caracteriza por la presión constante hacia algunos países latinoamericanos como el triángulo norte centroamericano condicionando los fondos de cooperación de los diferentes programas creados para detener el flujo de migrantes.

Con la victoria del demócrata Joseph Biden como presidente de los Estados Unidos en noviembre de 2020 se marcaría un giro en la política exterior del país norteamericano frente a China, Rusia y Latinoamérica. En ese orden, durante los debates presidenciales, Biden mostró una posición más abierta con respecto a las reformas migratorias necesarias para regularizar la situación de algunos sectores de la población inmigrante latinoamericana como los llamados "dreamers", ${ }^{9}$ al igual que estableció como premisa que de ser electo detendría la separación de niños y sus padres al llegar a la frontera del país de forma irregular (BBC, 2020). Aunque estas declaraciones son alentadoras para los inmigrantes, no significaría que la situación de deportaciones cambie drásticamente. ${ }^{40}$ Así, lo que podría verse en un futuro es un relanzamiento de una política exterior norteamericana más cercana a los países de la frontera sur bajo un soft power que permita contener las llamadas caravanas de migrantes, en su mayoría centroamericanos. 
Un acercamiento mayor y fortalecimiento con países latinoamericanos considerados clave a los intereses securitarios norteamericanos supondría indirectamente un obstáculo para la profundización de las relaciones entre Rusia y China en la región.

Bajo este contexto, sería poco probable que Guatemala, Honduras y El Salvador a pesar de que tienen relaciones diplomáticas con la Federación de Rusia, se aventuren a estrecharlas mediante acuerdos comerciales o políticas dada la dependencia con Estados Unidos; no obstante, el ofrecimiento de la vacuna Sputnik V a países latinoamericanos podrían ablandar esta posición bastante prudente con el país eslavo. Así las cosas, el panorama indica que Rusia tiene posibilidades de fortalecer su influencia y presencia en la región, sin embargo, aún dista mucho de igualarse en términos de intercambio y dependencia como sucede con Estados Unidos.

\section{CONCLUSIONES}

La Federación de Rusia ha experimentado diversos estadios en cuanto a su política exterior, tal como se ha hecho un breve recuento en títulos anteriores, ha pasado de un estilo prooccidental y defensivo a un enfoque multipolar y ofensivo para reemerger como potencia global. Las acciones exteriores enmarcadas en los veinte años del siglo XXI han sido suficientes para manifestar sus intenciones de un ascenso pragmático a la cima de una estructura internacional que durante los primeros años de la posguerra fría consideró haberle tratado con desprecio por la debilidad en diferentes ámbitos a raíz del desmembramiento de la URSS.

En esta reemergencia, América Latina juega un papel importante como espacio estratégico para la consecución de sus objetivos globales, la región ofrece diferentes ventajas no solamente como cliente en la compra de armamentos y maquinaria para la industria energética, sino por considerarse uno de los espacios de predominio estadounidense desde el siglo antepasado y pieza clave para la expansión de su ideología durante la época de la guerra fría a través del sostenimiento de dictaduras militares y gobiernos autoritarios. Aunque existió una relación comercial con la URSS, los lazos ideológicos se vieron distanciados con algunos partidos comunistas por la ruptura soviética con los comunistas chinos. En la posguerra fría estos acercamientos se mantuvieron, pero la Federación no buscaba hacer frente a la unipolaridad estadounidense, al menos en América Latina, por lo que el intercambio de mercancías no significó un problema para los norteamericanos.

Con la aplicación de la Doctrina de la Multipolaridad como base de la política exterior rusa a inicios del siglo XXI, las relaciones de la Federación fueron cada vez más asertivas en aquellos espacios considerados estratégicos para romper con la estructura de poder internacional que les había relegado a un espacio menor, por lo que formaron alianzas con los Estados emergentes en el grupo apodado periodísticamente como BRICS, plataforma que también ha utilizado para acercarse a otras regiones transhemisféricas buscando nuevos mercados donde expandir sus relaciones comerciales y vínculos políticos. La emergencia de una izquierda latinoamericana animosa de mayor autonomía frente a los Estados Unidos fue la oportunidad esperada para que las relaciones comerciales se vieran fortalecidas por medio de la venta de armamento y este intercambio sirvió a su vez para que Rusia tuviese más influencia en la región.

La posición de los Estados Unidos frente a estos acercamientos de la Federación de Rusia en América Latina se determina por la capacidad de influencia que ejerce el Estado ruso en desmedro de las relaciones con los Estados Unidos y que, entre otras cosas, ha servido para mantener algunos gobiernos que los norteamericanos consideran antidemocráticos como Venezuela y Nicaragua. Las 
relaciones cercanas de estos países con Rusia y China funcionan en una doble vía, por una parte, representan un movimiento disuasorio de estos Estados latinoamericanos frente a Estados Unidos y sus intenciones de derrocarles, y por otra, tanto para Rusia y China representan un enclave de la influencia lograda en la región frente a los estadounidenses.

Aunque podría creerse que las relaciones de Rusia con Latinoamérica están marcadas por la ideología de los gobiernos con quienes establece estos lazos, lo cierto es que el pragmatismo característico de Rusia en el marco de un realismo ofensivo dista mucho de esta aseveración. Las inversiones en países clave como Argentina, Brasil y México no obedecen a la presencia de mandatarios o ideología de gobiernos en específico, sino que se han logrado establecer y fortalecer a través del tiempo independientemente del tinte político del gobierno en turno, muestra de ello has sido los lazos que mantiene con Brasil después de destitución de Dilma Rousseff como presidenta y la relación estratégica con los gobiernos argentinos después de la era de los Kirchner. Aún con las tensiones entre el Kremlin y la Casa Blanca por la situación de Venezuela, queda claro que Rusia se mantendrá como socio comercial en la región y que ofrece una alternativa frente a los Estados Unidos para generar proyectos de inversión y apertura de mercados, así como oportunidades de cooperación técnica en proyectos energéticos.

Con la pandemia de COVID19 y el anuncio de Sputnik V, Rusia abrió posibilidades de aumentar su influencia en la región latinoamericana a través de ofrecer a varios países de la región como Brasil, Venezuela y México la posibilidad de colaborar con los ensayos clínicos en pacientes con el virus activo a fin de obtener resultados sobre la capacidad de la vacuna para neutralizar la enfermedad y, en caso de ser exitosa, paliar la situación de contagio y mortalidad en la región. Así se consideraría a estos países como los primeros en recibir la vacuna para inmunizar a sus poblaciones, claramente, a cambio de mantener el acompañamiento político y continuar reforzando las relaciones económicas entre estos y el país euroasiático.

En este orden de factores, hasta el momento, la presencia de Rusia en Latinoamérica no se ha visto mermada, y podría continuar aumentando a partir de las posibilidades de éxito relacionadas con la apertura de mercados farmacéuticos y de licencia para la producción de fármacos. Algo que puede resultar de especial relevancia si la Sputnik V resulta ser la cura para la pandemia de 2020; ante esa eventualidad Rusia se podría consolidar y legitimar como potencia mundial dentro de una estructura multipolar.

\section{BIBLIOGRAFÍA}

Alonso, A. (22 de agosto de 2020). La guerra geopolítica de las vacunas, la primera gran guerra del siglo XXI. El independiente. Obtenido de https://www.elindependiente.com/politica/2020/08/22/la-guerra-geopolitica-de-las-vacunas-la -primera-gran-guerra-del-siglo-xxi/\#: :text=La\%20guerra\%20geopol\%C3\%ADtica\%20por\%20logr ar.al\%20millonario\%20mexicano\%20Carlos\%20Slim.

Álvarez Portas, M. (2020). Identidad nacional y política exterior: un breve análisis de su conexión en el caso de Rusia. Documentos de Opinión IEEE, 1-24.

Badine El Yattioui, M. (2019/2020). El ALCA, ¿un proyecto geoeconómico permanentemente enterrado? Nueva Época(47), 344-367.

Banco Interamericano de Desarrollo. (2020). Plan de la Alianza para la Prosperidad del Triángulo Norte. Obtenido de BID: https://www.iadb.org/es/alianzaparalaprosperidad 
BBC Mundo. (4 de noviembre de 2016). El polémico San Vladimir de 11 metros que Putin acaba de inaugurar en el corazón de Moscú. Bristish Broadcasting Corporation. Obtenido de https://www.bbc.com/mund o/noticias-37874088

BBC Mundo. (21 de mayo de 2018). Elecciones en Venezuela: Nicolás Maduro gana las presidenciales según el Consejo Nacional Electoral y Henri Falcón cuestiona el resultado. Bristish Broadcasting Corporation. Obtenido de https://www.bbc.com/mundo/noticias-america-latina-44192065

BBC Mundo. (29 de marzo de 2019). Crisis en Venezuela: la creciente tensión entre Rusia y EE.UU. por sus posiciones respecto al gobierno de Maduro. Bistish Broadcasting Corporation. Obtenido de https://ww w.bbc.com/mundo/noticias-america-latina-47741527

Bermúdez, Á. (6 de febrero de 2019). Crisis en Venezuela: ¿qué busca Estados Unidos y por qué actúa ahora? Bristish Broadcasting Corporation. Obtenido de https://www.bbc.com/mundo/noticias-america-latin a-47126324

Berríos, R. (1990). Relaciones Económicas entre la Unión Soviética y América Latina . Comercio Exterior , 425-436.

Blasier, C., \& Vacs, A. (octubre- diciembre de 1983). América Latina frente a la Unión Soviética. (C. d. México, Ed.) Foro Internacional, 24(2), 199-211.

Cabeza, M. (2008). La religión como fuerza profunda en la Rusia contemporánea y en sus vínculos externos. En A. Busso, Fuerzas profundas e identidad. Reflexiones en torno a su impacto sobre la política exterior. Un recorrido de casos (págs. 171-182). Rosario : Universidad Nacional de Rosario .

Calduch Cervera, R. (1993). Dinámica de la Sociedad Internacional. Madrid: Ramón Areces.

Calduch Cervera, R. (1998). Métodos y Técnicas de Investigación en Relaciones Internacionales. (17), 91-106. Madrid, España: Universidad Complutense de Madrid. Obtenido de http://www.scielo.org.bo/scielo.p hp?script=sci_arttext\&pid=S0040-29151993000100008\&lng=es\&tlng=es.

Cámara de Comercio e Industria Argentino Rusa. (s.f.). Exportaciones argentinas a Rusia por USD 814 millones durante 2019. Obtenido de Cámara de Comercio e Industria Argentino Rusa: https://www.caciar.com. ar/novedades/exportaciones-argentinas-a-rusia-por-usd-530-millones-de-dolares-durante-2017/

Carreras, C. (1997). Los Estados Unidos y el Mercado Común Centroamericano a finales de los años 50. Anuario de Estudios Centroamericanos .

CEPAL Subsede México. (2007). DR-CAFTA: aspectos relevantes seleccionados del Tratado y reformas legales que deben realizar a su entrada en vigor los países de Centroamérica y la República Dominicana. Estudios y Perspectivas.

CIDOB. (2010). La política exterior de la Federación Rusa. Anuario Internacional de CIDOB, 493-503.

Cortes, R. (2019). 3 de diciembre de 1989- A 30 años de la Cumbre de Malta. Obtenido de Instituto de Relaciones Internacionales: https://www.iri.edu.ar/index.php/2019/12/17/3-de-diciembre-de-198 9-a-30-anos-de-la-cumbre-de-malta/

Criterio hn. (11 de octubre de 2018). Fondos del Plan de la Alianza para la Prosperidad se alejan de Honduras. Criterio.hn. Obtenido de https://criterio.hn/fondos-del-plan-de-la-alianza-para-la-prosperidad-se-ale jan-de-honduras /

De Freitas Coutinho, M. A. (enero- abril de 2020). Estrategia Nacional de la Federación de Rusia: aspectos geopolíticos. Coleçáo Meira Mattos, 14(49), 1-26.

De la Gandara Frieyro, M. (2018). La política exterior rusa en la zona postsoviética: el arco de inestabilidad Báltico-Caucásico. Revista de Pensamiento Estratégico y Seguridad CISDE, 45-65.

de Pedro, N., Martínez, I., \& Sökmen, M. (2018). Rusia, Irán y Turquía ¿una estrategia común en Siria? Notes Internacionals CIDOB(196). 
Deustch Welle. (18 de mayo de 2018). Merkel y Putin reafirman gaseoducto Nord Stream II. Deustch Welle. Obtenido de https://www.dw.com/es/merkel-y-putin-reafirman-gasoducto-nord-stream-ii/a-43846 $\underline{914}$

Deustche Welle. (16 de diciembre de 2014). Rusia y América Latina: tan lejos y tan cerca. Deustche Welle. Obtenido de https://www.dw.com/es/rusia-y-am\%C3\%A9rica-latina-tan-lejos-tan-cerca/a-1776813 $\underline{5}$

Deutsh Welle. (29 de noviembre de 2008). Rusia exhibe músuculo y billetera en América Latina. Deustch Welle. Obtenido de https://www.dw.com/es/rusia-exhibe-m\%C3\%BAsculos-y-billetera-en-am\%C3\% A9rica-latina/a-3836392

Ecu Red. (s.f.). Ecu Red. Obtenido de Pacto de Varsovia: https://www.ecured.cu/Pacto_de_Varsovia

Ecu Red. (s.f.). Unión Soviética. Obtenido de Ecu Red: https://www.ecured.cu/Uni\%C3\%B3n_Sovi\%C3\%A9 tica\#Geograf.C3.ADa

Embajada de Rusia en México. (s.f.). Rusia. Obtenido de Embajada de la Federación de Rusia en los Estados Unidos Mexicanos : https://mexico.mid.ru/es/rusia\#: :text=Rusia\%20es\%2C\%20junto\%20con\%20 China,Mongolia\%20y\%20Corea\%20del\%20Norte.

Enciclopedia de Historia. (2018). Pacto de Varsovia. Obtenido de Enciclopedia de Historia: https://enciclop ediadehistoria.com/pacto-de-varsovia/

EOM. (7 de noviembre de 2018). Un país de inmigrantes. Obtenido de El Orden Mundial : https://elordenm undial.com/mapas/de-donde-proceden-los-inmigrantes-en-estados-unidos/

EOM. (26 de mayo de 2020). ¿Qués es Petrocaribe? Obtenido de El Orden Mundial: https://elordenmundia l.com/que-es-petrocaribe/

Garay Vera, C. (julio- diciembre de 2010). La Reemergencia de Rusia en el Mundo y América Latina. (A. N. Estratégicos, Ed.) Revista Política y Estrategia(116), 143-168.

García Estrada, Á. (2020). Cambio climático y aproximación de las potencias al Ártico. Documento de Opinión,. Documento de Opinión IEEES, 1-27.

García, P. (2012). Rusia y América Latina: las agendas compatibles para el futuro. Oasis(17), 65-87.

Glejdura, S. (1962). La Política Exterior de la URSS (1945-1962). Obtenido de Dialnet Unirioja : http://www.c epc.gob.es/Controls/Mav/getData.ashx?MAVqs= aWQ9MzMzNDcmaWRIPTEwMzcmdXJsPTEzJm5h bWU9UlBJXzA20V8wNDYucGRmJmZpbGU9UlBJXzA20V8wNDYucGRmJnRhYmxhPUFydGljdWxvJmN vbnRlbnQ9YXBwbGljYXRpb24vcGRm

Hernández Campos, A. (1997). La solución negociada de los conflictos: el caso de la guerra de la antigua Yugoslavia. (I. d. Internacionales, Ed.) Agenda Internacional, 45-80.

Historia Siglo 20. (2003). La Guerra Fría. Obtenido de Historia de las Relaciones Internacionales durante el siglo XX: http://www.historiasiglo20.org/GF/1962-75.htm

Kouzmine, V. (diciembre de 2001). El comercio entre América Latina y los países de Europa Central y Oriental en los años Noventa. (CEPAL, Ed.) CEPAL-SERIE Comercio Internacional, 1-60.

Kurjak, J. (2001). Rusia en los Balcanes. Revista Dossier(6), 35-50. Obtenido de http://www.istor.cide.edu/ archivos/num_6/dossier2.pdf

La Vanguardia. (marzo de 2019). Gazprom Neft asegura que no abandonará el proyecto petrolero en Venezuela. La Vanguardia. Obtenido de https://www.lavanguardia.com/vida/20190328/461310641 205/gazprom-neft-asegura-que-no-abandonara-el-proyecto-petrolero-en-venezuela.html

Leiva Van de Maele, D. (2017). Russia is back: análisis de la evolución de la política exterior rusa en la "era Putin". (I. d. Internacionales, Ed.) Estudios Internacionales(187), 9-42.

Makarychev, A. (diciembre de 2011). Rusia en un mundo multipolar: El papel de las identidades y los "mapas cognitivos". CIDOB dáfers internationals(96), 25-43. 
Malamud, C. (9 de octubre de 2013). Rusia y América Latina: una relación basada en la nostalgia, pero no sólo.... blog del Real Instituto Elcano. Obtenido de https://blog.realinstitutoelcano.org/rusia-y-americ a-latina-una-relacion-basada-en-la-nostalgia-pero-no-solo/

Marquez Díaz, A. (2014). Política Exterior Soviética y Rusa. Análisis histórico de su evolución 1979-2008. Barcelona, España: Universitat de Barcelona.

Martínez Carmena, M. (18 de mayo de 2018). La Organización del Tratado del Atlántico Norte y la ampliación al Este: ¿hasta Ucrania? Revista de Relaciones Internacionales, Estrategia y Seguridad, 13, 123-151. Obtenido de https://revistas.unimilitar.edu.co/index.php/ries/article/view/3134/3032\#toc

Montes, M. (2018). Regreso a la Guerra Fría? Las relaciones Estados Unidos-Rusia desde 1992 hasta la actualidad y sus implicancias para América Latina. XIII Congreso Nacional y VI Congreso Internacional sobre Democracia de la Universidad de Rosario (págs. 1-26). Rosario: Facultad de Ciencia Política y Relaciones Internacionales de la Universidad de Rosario.

Moure Peñín, L. (2015). El Realismo en la Teoría de las Relaciones Internacionales: génesis, evolución y aportaciones actuales. En C. Del Arenal, \& J. A. Sanahuja, Teoría de las Relaciones Internacionales . Madrid: Tecnos.

Paez Montalbán, R. (2013). El proceso de negociación del Grupo de Contadora. Revista Mexicana de Política Exterior, 63-74. Obtenido de https://revistadigital.sre.gob.mx/images/stories/numeros/ne2013/pae zm.pdf

Pearson, F., \& Rochester, M. (2000). Relaciones Internacionales: situación global en el siglo XXI. Bogotá: Mc Graw Hill.

Plokhy, S. (2015). El último imperio. Los días finales de Unión Soviética. (P. Sauras, Trad.) Turner Noema.

Preciado Coronado, J. (2010). La construcción de una geopolítica crítica desde América Latina y el Caribe. Hacia una agenda de investigación regional. Geopolítica (s), 65-94.

RIJIA. (2012). Esquemas y organismos de la integración latinoamericana. Obtenido de Red Internacional de Juristas para la Integración Americana: http://www.rijia.org/esquemas-y-organismos-de-la-integraci \%C3\%B3n-americana.html

Rodríguez Hernández, L. (2019). Las relaciones Rusia- América Latina y Caribe en el Contexto del fin de la Guerra Fría. Pensamiento Propio, 111-142.

Rühle, M. (2015). La ampliación de la OTAN y Rusia: mitos y realidades. Revista de la OTAN. Obtenido de https://www.nato.int/docu/review/2014/Russia-Ukraine-Nato-crisis/Nato-enlargement-Russia/ ES/index.htm

Sahagún, F. (1989). Perestroika. BBC Mundo, págs. 15-58.

Sánchez Andrés, A. (2014). ¿De la crisis al resurgimiento? La industria militar rusa en el siglo XXI. Nueva Sociedad , 187-198.

Sánchez de Rojas Díaz, E. (2016). Repensando la Geopolítica de América Latina. ¿Es necesario un estudio geopolítico de América del Sur? Documento de Análisis de IEEE, 1-27.

Sánchez Ramírez, P. T. (2010). La Federación Rusa y su entorno geopolítico en los nuevos arreglos mundiales de poder. Política y Cultura(34), 159-185.

Schulze, P. (noviembre-diciembre de 1985). La Dinámica del Inmovilismo. El Sistema Soviético entre Crisis y Reforma. Nueva Sociedad(80), 31-32. Obtenido de https://nuso.org/media/articles/downloads/13 31_1.pdf

Schuster, M. (noviembre de 2017). ¿El "retorno ruso" a América Latina? Nueva Sociedad. Obtenido de https ://nuso.org/articulo/rusia-entre-nosotros/

Schuster, M. (noviembre de 2017). ¿El "retorno ruso" a América Latina? Nueva Sociedad. Obtenido de https ://nuso.org/articulo/rusia-entre-nosotros/ 
Serbín, A. (2018). América Latina y el Caribe frente a un nuevo orden mundial: crisis de la globalización, reconfiguración global del poder y respuestas regionales. En C. R. Sociales, \& A. Serbin (Ed.), América Latina y el Caribe frente a un Nuevo Orden Mundial: Poder, Globalización y Respuestas Regionales (págs. 13-36). Buenos Aires, Argentina: Icaria Editorial.

Sheykina, V. (2010). Historia de las Relaciones de Rusia y Latino América: Evolución y Prospectiva. Revista Electrónica Iberoamericana, 4(1), 181-228.

Simonof, A. (1994). Origen, Desarrollo y Futuro de la C.E.I. Obtenido de Anuario de Relaciones Internacionales : http://www.iri.edu.ar/publicaciones_iri/anuario/A94/A1EUEST3.html

Sitenko, A. (2017). Cooperaciones Estratégicas Rusia- América Latina: Un balance preliminar. Rusia $e$ Iberoamérica en el mundo globalizante: historia y perspectivas, (págs. 1185-1196). San Petersburgo.

Soames, N. (2019). Envolving Security in North Atlantic. NATO Defence and Security Committee.

Sputnik News. (11 de noviembre de 2019). El jefe del Consejo Rusia-Brasil expresa la disposición de cooperar de empresas rusas. Sputnik News. Obtenido de https://sptnkne.ws/AuhW

Statista. (octubre de 2020). Número de personas contagiadas a causa del coronavirus (COVID19) en América Latina y El Caribe al 25 de septiembre de 2020. Obtenido de Statista: https://es.statista.com/estadistic as/1105336/covid-19-numero-fallecidos-america-latina-caribe/

teleSUR. (12 de mayo de 2016). Rusia califica de inaceptable la injerencia externa en Brasil. teleSur. Obtenido de https://www.telesurtv.net/news/Rusia-califica-de-inaceptable-la-injerencia-externa-en Brasil-20160512-0026.html

Terradas, N. (12 de marzo de 2009). El dilema de seguridad y su importancia para el estudio de las relaciones internacionales. Letras Internacionales(88), 1-5. Obtenido de https://revistas.ort.edu.uy/letras-intern acionales/article/view/1627/1607

Varas, A. (1981). América Latina y la Unión Soviética: Relaciones Interestatales y Vínculos Políticos. Relaciones Internacionales de América Latina (págs. 1-49). San Juan: FLACSO.

Varas, A. (1987). Las relaciones soviético-latinoamericanas bajo la hegemonía regional de los Estados Unidos. América Latina y la Unión Soviética: Una nueva relación , 9-39.

Vargas Hernández, J. G. (2009). El realismo y el neorrealismo estructural. (U. N. México, Ed.) Estudios Políticos, 9(16), 112-124. Obtenido de https://www.redalyc.org/pdf/4264/426439540006.pdf

Velásquez Rivera, E. d. (enero- abril de 2002). Historia de la Doctrina de la Seguridad Nacional. Convergencia(27), 11-39.

Vinagre, E. (1 de diciembre de 2008). Maniobras militares Venezuela-Rusia: más ruido que nueces. Deustch Welle. Obtenido de https://www.dw.com/es/maniobras-militares-venezuela-rusia-m\%C3\%A1s-ruid o-que-nueces/a-3840540

Wallace, A. (8 de septiembre de 2020). Vacuna contra el covid-19: cuál será el rol de América Latina en el desarrollo y fabricación de Sputnik V, la vacuna rusa contra el coronavirus. British Broadcasting Corporation. Obtenido de https://www.bbc.com/mundo/noticias-america-latina-54064118

Zubelzú, G. (2008). Entender a Rusia a través de sus fuerzas profundas: dificultades y desafíos de una reflexión recurrente. En A. Busso, Fuerzas profundas e identidad. Reflexiones en torno a su impacto sobre la política exterior. Un recorrido de casos (págs. 125-141). Rosario: Universidad Nacional de Rosario.

\section{REFERENCIAS}

ALADI (2019), Países Miembros, http://www.aladi.org/sitioaladi/

BBC Mundo (2017), ¿Por qué Rusia prohibió a los Testigos de Jehová?, https://www.bbc.com/mundo/not icias-internacional-39665095 
BID (2016), Algunos conceptos básicos sobre extractivas en América Latina y el Caribe, Energía para el Futuro, https://blogs.iadb.org/energia/es/algunos-conceptos-basicos-sobre-extractivas-en-americalatina-y-elcaribe/\#: :text=\%C2\%BFPor\%20d\%C3\%B3nde\%20empezamos\%3F,esenciales\%20para \%20la\%20econom\%C3\%ADa\%20global

BID (2020), Plan de la Alianza para la Prosperidad del Triángulo Norte, 2020, https://www.iadb.org/es/a lianzaparalaprosperidad

Ecu Red (s.f), Iniciativa de Defensa Estratégica, https://www.ecured.cu/Iniciativa_de_Defensa_Estrat\%C3 \%A9gica

EcuRed (s.f.), CAME, https://www.ecured.cu/CAME

Enciclopedia de Historia (s.f.), Pacto de Varsovia, https://enciclopediadehistoria.com/pacto-de-varsovia/

Granma (s.f.), Petrocaribe, http://www.granma.cu/granmad/secciones/petrocaribe/que-es/que-1.html

Hass, M. (2011) Russia's Military Reforms: Victory after Twenty Years of Failure? , Revista Clingendael $N^{\circ} 5$, pág. 13-16

Hernández Campos, A. (1997), La Solución Negociada de los Conflictos: el caso de la guerra de la antigua Yugoslavia, Revista Agenda Internacional, Instituto de Estudios Internacionales, págs. 45-80

Johns Hopkins University (2020), Coronavirus Resource Center, https://coronavirus.jhu.edu/map.html

La Vanguardia (2019), Gazprom Neft asegura que no abandonará el proyecto petrolero en Venezuela, https://www.lavanguardia.com/vida/20190328/461310641205/gazprom-neft-aseguraque-no-abandonara-el-proyecto-petrolero-en-venezuela.html

López Serrano, A.(2003), Los Eslavos. El mayor grupo cultural de Europa, Grandes Ámbitos Culturales de la Historia Europea, Universidad Carlos III de Madrid, https://e-archivo.uc3m.es/bitstream/handle/100 16/12350/eslavos_lopez_2003.pdf?sequence=1\&isAllowed=y

OEA (s.f.), La Iniciativa Regional de Seguridad para América Central: https://www.oas.org/ext/es/seguridad /red-prevencion-crimen/Recursos/Multimedios/ArtMID/1608/ArticleID/1373/EL-SALVADOR-INIC IATIVA-REGIONAL-DE-SEGURIDAD-PARA-AM\%C3\%89RICA-CENTRAL-CARSI

Rusopedia (s.f.), El Día de Bautismo de Rusia, TV- Novosti, https://rusopedia.rt.com/datos_basicos/fiestas /issue_52.html

Seguridad ciudadana, derechos humanos y estado de derecho, https://2009-2017.state.gov/documents/o rganization/210231.pdf

Velásquez Rivera, E. (2002), Historia de la Doctrina de la Seguridad Nacional, Revista Convergencia, Número 27, pág.13

NOTAS

1 Esto fue más evidente en el apoyo a Osetia del Sur durante las hostilidades en el conflicto osetio- georgiano de 2008.

2 En 2008 Rusia había suscrito contratos con México, Perú, Colombia, Brasil y Cuba. También sostuvo negociaciones con otros Estados como posibles compradores, entre estos se destacan Chile, Uruguay y Ecuador. (Garay Vera, C., 2010)

3 Véase Título 3 Características Geopolíticas de América Latina.

4 Estos se definen como aquellos factores de naturaleza exógena, escapando del control de los Estados, entre ellos se encuentran: la geografía, los Estados vecinos y la estructura del sistema internacional. (Pearson, F. \& Rochester, M., 2000)

5 Albania, Alemania Oriental, Bulgaria, Checoslovaquia, Hungría, Polonia y Rumanía

6 Entre estos incidentes se destacan las protestas en Hungría de 1956 y la llamada Primavera de Praga en Checoslovaquia en 1968. (Enciclopedia de Historia, s.f.) 
Llamada así por Leonid Breznev, secretario del Partido Comunista Soviético y líder de la URSS desde 1966 hasta su muerte en 1982

8 En el 2001, de cinco secciones de las fuerzas armadas rusas se pasó a tres: el Ejército, la Marina y la Fuerza Aérea. (Hass, M., 2011) pág. 13-16

9 Doctrina bajo la cual las fuerzas armadas latinoamericanas se volcaron al control interno de la población y desbaratar cualquier proceso de insurgencia que llevara a una revolución de corte comunista con el apoyo y asesoría estadounidense. (Velásquez Rivera, E. 2002)

10 Esta invasión se llevó a cabo amparándose en el Tratado de Amistad, Buena Vecindad y Cooperación entre la Unión de Repúblicas Socialistas Soviéticas y la República Democrática de Afganistán con el fin de instalar en Kabul un gobierno afín a los intereses de la URSS, sin embargo, el asesinato del candidato apoyado por los soviéticos Braback Karmal por órdenes de Jafizulá Amín, constituyó la razón para que el ejército rojo invadiera el país. (Marquez Díaz, A., 2014)

11 Era un grupo formado por Estados Unidos, Reino Unido, Francia, Italia, Alemania y Rusia con el fin de crear un plan para llegar a la solución del conflicto de Bosnia Hernzegovina, sin embargo, este plan no fue aceptado por las partes por considerarlo desfavorable a sus intereses. (Hernández Campos, A., 1997, págs. 45-80)

"Esta iniciativa fue popularmente conocida con el nombre de Guerra de las Galaxias y tenía como objetivo la construcción de bases espaciales que permitieran evitar un ataque nuclear a territorio estadounidense, algunas de sus propuestas se quedaron en meros proyectos dado que la tecnología para llevarla a cabo no estaba desarrollada y el gasto en lograr su existencia era muy costoso." (Ecu Red, s.f)

13 Estos países son Hungría, Polonia y Rumanía, los cuales iniciaron el proceso de integración a la OTAN inmediatamente después de abolido el Pacto de Varsovia.

14 Los pueblos eslavos se dividen en 3 tipos: los eslavos occidentales que incluyen a pueblos como los polacos, checos, eslovacos, serbios, eslovincios, casubios y lusacianos; los eslovacos meridionales que se encuentran en los países de la península bálcánica; y, los eslovacos orientales que incluyen a rusos, bielorrusos y ucranianos. (López Serrano, A., 2003)

15 En la autopercepción del pueblo ruso, el país ha reemergido como potencia, puesto que se mantuvo como centro de poder durante la época de la bipolaridad.

16 "Se le da el nombre del Bautismo de Rusia al bautismo colectivo y conversión a la iglesia ortodoxa de los habitantes de Kiev en el año 988 mandado por el príncipe Vladimir, se celebra cada 28 de julio y en 2008, la Iglesia exhortó a los Estados de Bielorrusia y Ucrania unirse a esta celebración a nivel estatal." (Rusopedia, s.f) En 2017 la Corte Suprema de Justicia declaró organización extremista a los Testigos de Jehová prohibiendo la existencia de esta secta religiosa en Rusia. Para algunos fieles de esta corriente, esta situación se debe a la protección que el gobierno da a la Iglesia Ortodoxa para limitar la diversificación de creencias en el país, de forma que poner en peligro la primacía ortodoxa en la sociedad rusa se considera una amenaza a la seguridad nacional, como lo dejaron entrever algunas personas entrevistadas por la BBC. (BBC Mundo 2017)

18 "América Latina y el Caribe cuenta con alrededor de 20\% de las reservas convencionales de petróleo del mundo, el $4 \%$ de las reservas de gas y los principales yacimientos de cobre, mineral de hierro, plata, oro, zinc, carbón y otros minerales esenciales para la economía global. La región también posee reservas considerables de petróleo y gas no convencional. Estas riquezas naturales hacen de la región la principal fuente mundial de metales y la segunda fuente más importante de petróleo." (BID, 2016)

19 Comisión Económica para América Latina y El Caribe

20 Se denomina así a esta corriente de geopolítica crítica en donde se llevan a cabo procesos que se alejan de los objetivos geopolíticos de las potencias en regiones de interés. (Preciado Coronado, J. 2010, págs 65-94)

21 Una integración económica que comprende a Argentina, Brasil, Paraguay, Uruguay y Venezuela.

22 Tiempo después el proyecto ALBA cambió de nombre y actualmente se denomina Alianza Bolivariana para los Pueblos de Nuestra América manteniendo las mismas siglas que lo identificaron anteriormente.

23 "Actualmente Petrocaribe está formado por Venezuela, Cuba, República Dominicana, Nicaragua, Antigua y Barbuda, Bahamas, Dominica, Granada, Guyana, Jamaica, Surinam, Santa Lucía, San Cristóbal y Nieves, San Vicente y las Granadinas, Honduras (que fue suspendido por el golpe de Estado a Manuel Zelaya en 2009) y Haití, también participan como observadores Ecuador y Bolivia." (Granma, s.f)

24 Esta iniciativa planteaba la respuesta militarizada ante el problema de narcotráfico, una copia del Plan Colombia creado para el mismo fin.

25 Fundado con el nombre de Plan Puebla- Panamá en alusión a las zonas objetivo planteadas en el acuerdo.

26 Compuesto por Guatemala, El Salvador y Honduras 
27 Este plan tiene a su base 4 ejes estratégicos que contemplan el desarrollo de capacidades económicas y sociales de las poblaciones más vulnerables en temas de seguridad pública y económica. La financiación de este plan está determinada por una colaboración entre los países centroamericanos y el gobierno de Estados Unidos. (BID, 2020)

28 Complementa las estrategias y programas que los países de América Central llevan a cabo por cuenta propia y en colaboración con otros países. Estados Unidos ajusta su ayuda de conformidad con la Estrategia de seguridad regional del Sistema de Integración Centroamericana (SICA) y también recurre a la experiencia y el trabajo de otros países, de instituciones financieras internacionales, el sector privado y la sociedad civil. (OEA, s.f.)

29 El golpe de Estado ejecutado por Augusto Pinochet en 1973 fue un revés a esta tesis, no obstante, la URSS se limitó a protestar por la vinculación estadounidense con esta operación y posterior dictadura, tales declaraciones no trascendieron a más para no alterar el proceso de distensión al que se había llegado, al igual que lo hizo Estados Unidos con la Doctrina Breznev en Checoslovaquia en años anteriores.

30 Consejo de Ayuda Mutua Económica era una organización formada por la URSS, Bulgaria, Checoslovaquia, Hungría, Polonia y Rumania. (EcuRed, s.f.)

31 Asociación Latinoamericana de Integración, nació en 1980 como organismo regional y actualmente está compuesta por 13 países miembros: Argentina, Bolivia, Brasil, Chile, Colombia, Cuba, Ecuador, México, Pamaná, Paraguay, Perú, Uruguay y Venezuela. (ALADI, 2019)

32 Acrónimo dado al foro que reúne a las potencias emergentes: Brasil, Rusia, India, China y, que en este caso incluye a Sudáfrica.

33 Refiérase al apartado 3 de este trabajo.

34 Politólogo del Instituto Alemán de Estudios Globales y Regionales de Hamburgo

35 Es la empresa gasística más grande de Rusia, aunque es de propiedad estatal su organización responde a un esquema de empresa privada. Está dedicada a la producción, almacenamiento, distribución y procesamiento de gas, incluye la generación y comercialización de calor y energía eléctrica. Su filial Gazprom Neft está encargada de los negocios sobre hidrocarburos. En Gazprom, About Gazprom, https://www.gazprom.com/about/

36 Es una empresa petrolera venezolana controlada en un $60 \%$ por Petróleos de Venezuela SA (PDVSA). (La Vanguardia 2019)

37 Según estadísticas de la Universidad Johns Hopkins hasta el día 5 de noviembre de 2020. (Johns Hopkins University, 2020)

38 Alemania, China, Cuba, Estados Unidos, Reino Unido y Rusia

39 Se conoce como dreamers (soñadores) a los jóvenes inmigrantes que fueron introducidos por sus padres en territorio estadounidense de forma ilegal a temprana edad.

40 Durante los períodos de B. Obama la cantidad de deportados latinoamericanos superó los 3 millones de inmigrantes. 